\title{
دور شبكات التواصل الاجتماعية في تفعيل التطوع الاكتروني من وجهة نظر خريجات جامعة الأميرة نوره
}

\author{
إعـــإ \\ د. أمل سفر حسين القحطانى

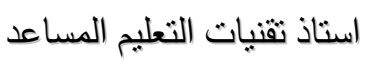 \\ كلية الثربية - جامعة الأميرة نورة
}

مجلة الدراسات التريوية والأنساتية ـ كلية التربية ـ جامعة دمنهور

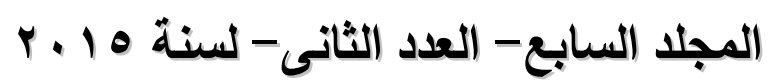


دور شبكات التواصل الاجتماعية في تفعيل التطوع الاكتروني فى جامعة الأميرة نورا د. أمل القحطانى 


\section{دور شبكات التواصل الاجتماعية في تفعيل التطوع الاكتروني من وجهة}

\section{نظر خريجات جامعة الأميرة نوره}

د. أمل سفر القحطانى

\section{المقدمة}

برزت في الآونة الأخيرة شبكات التواصل الاجتماعيةعلي شبكة الإنترنت وحظيت بانتشار كبير علي الصعيد العالمي، بل وقد بات بعضها من أكثر المواقع زيارة في لإلي العالم حتي إنها أصبحت تطغي علي ما كان يعرف في علم الاجتماع بـ ( المكان

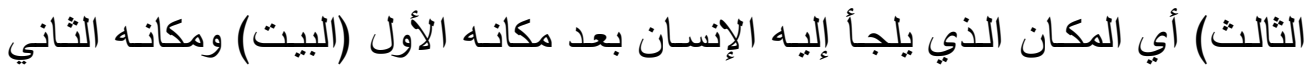

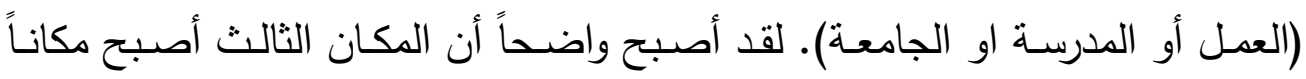

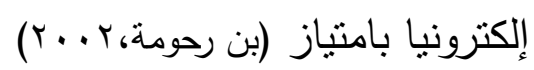

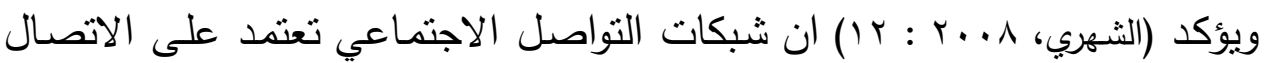

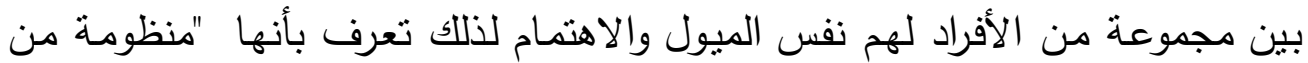
الثبكات الإلكترونية التي تسمح للمشرك فيها بإنشاء موقع خاص به، ومن ثم ربطه

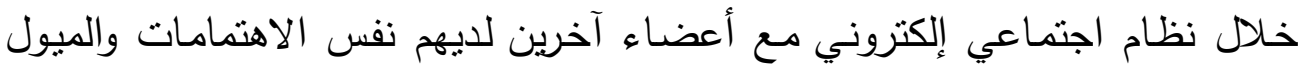

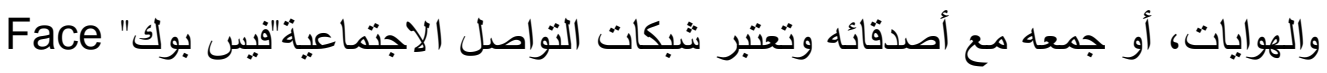

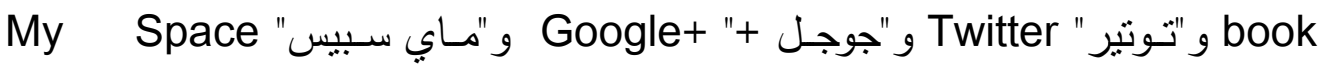

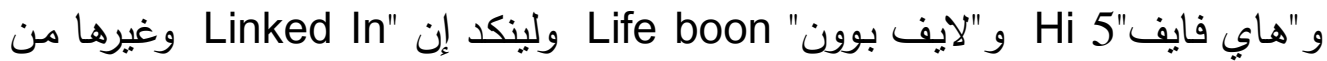

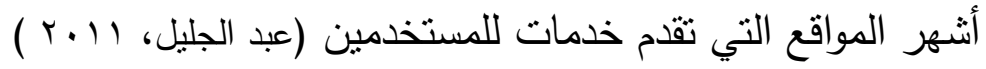
وتظهر الإحصاءات العالمية نزايد الإقبال علي استخدام شبكات التواصل الاجتماعية

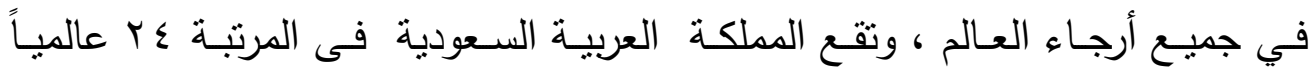

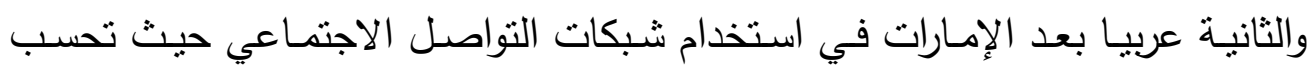

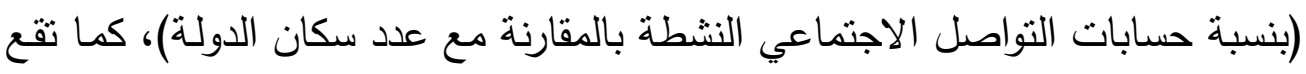

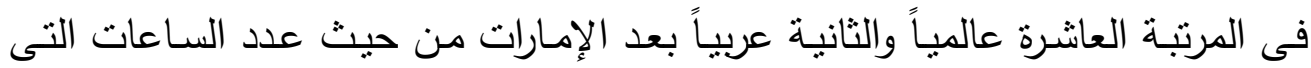

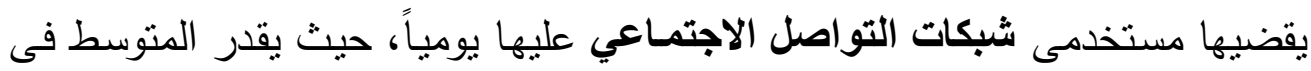


المملكة بـ ب ساعات، بزيادة T، • ساعة عن المتوسط العالمى، وتقع فى المرتبة سب

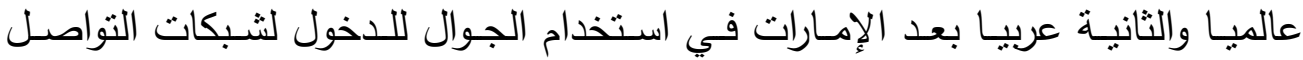
الاجتمـاعي فنجد أن OY\% من مستخدمى شبكات التواصل الاجتمـاعي فى المملكة

يخخلون عن طريق الجوال، بزيادة r\% عن المتوسط العالمى (جريدة السياسة، ع (بr) واستطاعت شبكات التواصل الاجتماعية مثل "الفيس بوك" وغيرها ك "توتير" و "لينكد

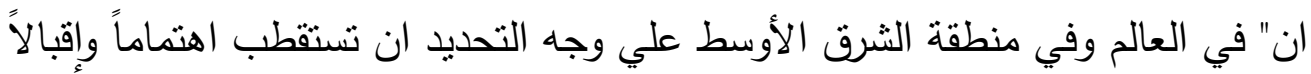

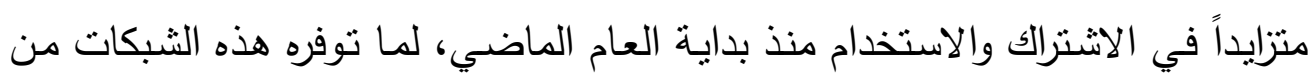

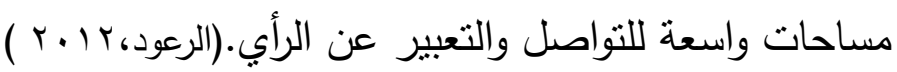
مشكلة الاراسة وأسئلتها تظهر الإحصاءات العالمية تزايد الإقبال علي استخدام شبكات التواصل الاجتماعية والهدف من هذه الشبكات هو تبادل الآراء والأفكار والتقدم بمقترحات وحلول شبكات إلكترونية تجمع للمشكلات التي تواجه المنشاركين في الحوار ، فهى عبارة عن "مجموعة من الأفراد ذوي ميول واتجاهات متقاربة، للتواصل وتبادل الأفكار والآراء والمقترحات ل

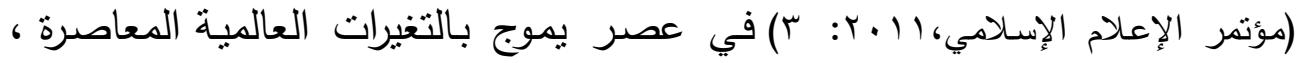

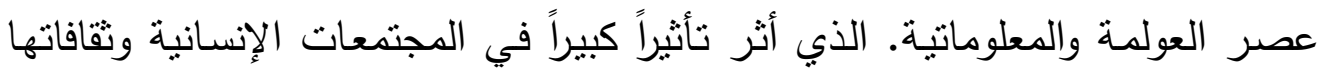
وأنساقها القيمية السائدة.

وفي الوقت الذي نتـهد فيه المملكة العربية السعودية تحديات اجتماعية واقتصادية

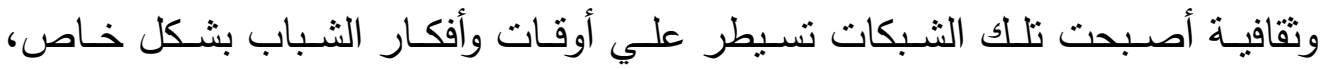
فأصبحوا يقضون اغلب أوقاتهم وراء شاشات الكمبيوتر باستخدام هذه المواقع لأغراض تختلف باختلاف احتياجاتهم في حياتهم اليومية لترسم بتردداتها إيقاع يومهم، وبهذا فهي

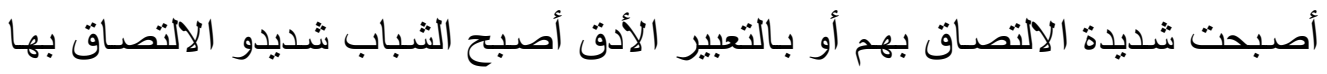
والتماهي مع وسائلها المتعددة . وتشير مراجعة التراث العلمي إلي وجود دراسات - محدودة جدا- حاولت الوقوف علي فاعليـة استخدام تلك الثبكات في تتميـة العمل التطوعي الالكتروني والفوائد 
المتحققة منها، الا انه لا توجد دراسات كافية تهتم بالوقوف علي استخدام فئة الثباب

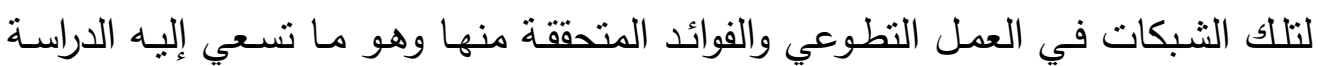
الحالية. وبناء علي ذلك تتلخص مشكلة الدراسة في الاسئلة التالية:

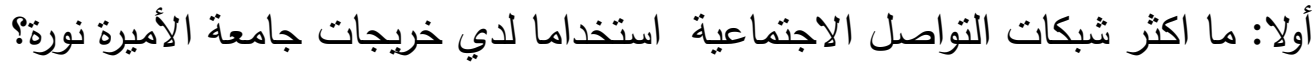
ثانيا : ما دور شبكات التواصل الاجتماعية في تتمية العمل التطوعي الالكتروني من

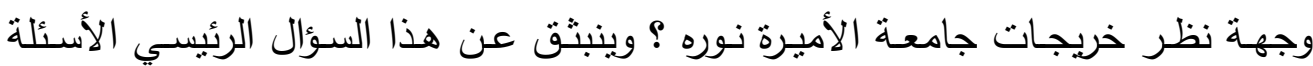
التالية:

ا .ما مدي الوعي بأهمية العمل التطوعي من وجهة نظر خريجات جامعة الأميرة نوره؟

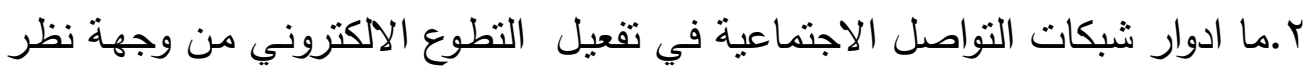

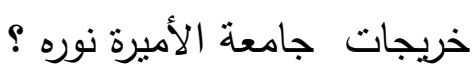
r.ما معوقات تفعيل التطوع الالكتروني عبر شبكات التواصل الاجتماعية من وجهة

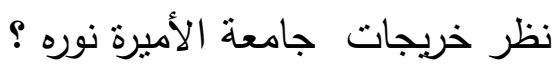
ع.ما هي اهم الاعمال التطوعية التي يمكن القيام بها عبر شبكات التواصل الاجتماعية

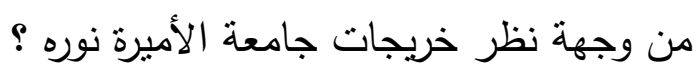
اهداف الارباسة وجنة •التعرف علي مدي الوعي بأهمية العمل التطوعي من وجهة نظر خريجات جامعة الأميرة نوره •التعرف علي ادوار شبكات التواصل الاجتماعية في تفعيل التطوع الالكتروني من وجهة نظر خريجات جامعة الأميرة نوره . •التعرف علي معوقات تفعيل التطوع الالكتروني عبر شبكات التواصل الاجتماعية من وجهة نظر خريجات جامعة الأميرة نوره •التعرف علي اكثر وسائل التواصل استخداما لدي خريجات جامعة الأبرة نوره الأميرة نورة •التعرف علي اهم الاعمال التطوعية التي يمكن القيام بها عبر شبكات التواصل الاجتماعية من وجهة نظر خريجات جامعة الأميرة نوره . 


\section{أهمبة الاراسة}

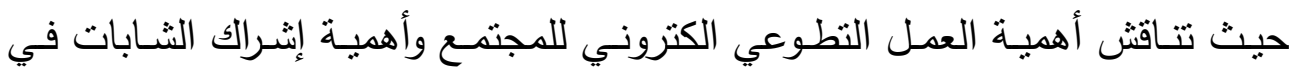
نطوير مجتمعاتهم من خلال شبكات التواصل الاجتماعي. •تتمية حب العمل الخيري والمبادرة لدي الثـابات من خلال تتميـة التطوع الإلكتروني لايهن دون الحاجة الي الذهاب لمؤسسة خيرية او اجتماعية.

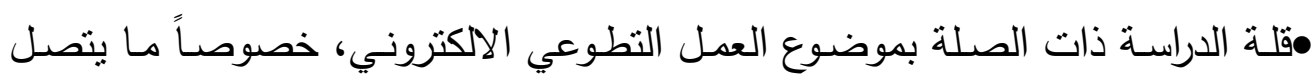
منها بمشاركة الثابات بالعمل التطوعي الالكتروني. •يتوقع أن يستقيد من نتائج هذه الدراسـة عدد من المؤسسـات الاجتماعية والثـبابية والتعليمية.

\section{متغيرات الاراسية}

المتغيرات المستقلة: وهي شبكات التواصل الاجتماعية.

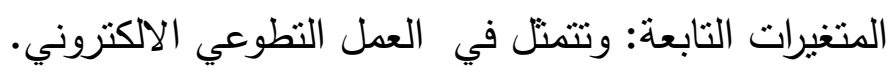

\section{منهرية الدراسية}

تعتمد هذه الدراسـة علي المنهج الوصفي وفي إطـاره تقوم الدراسـة بشكل رئيسي علي

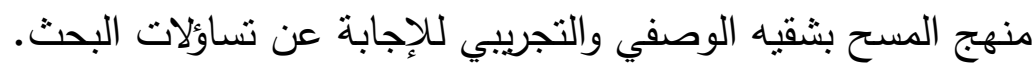
نوع الاراسة:

تعد هذه الدراسة من البحوث الوصفية التي أهم أوصافها وصف الظواهر والتعرف على

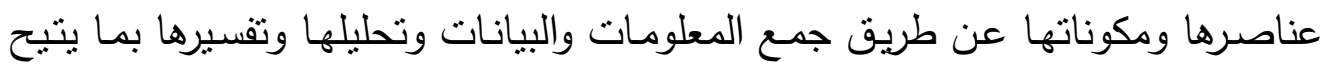
تقديم صورة دقيقة وموضوعية عن الظاهرة (السيد عمر، ؟99 19 ). إضافة إلى أنها تركز على وصف طبيعة وسمات وخصائص مجتمع معين أو موقف معين، أو جماعة أو فرد معين، وتكرارات حدوث الظاهرات المختلفة 


\section{مصطاح الابة}

\section{شبكات التواصل الاجتماعية}

هي مصطلح يطلق على مجموعة من المواقع على الإنترنت، تتيح التواصل بين

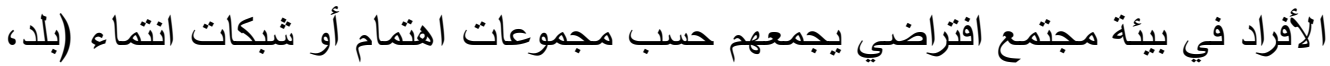
جامعة، مدرسة، شركة.... إلخ)، كل هذا ينت عن طريق خدمات التواصل المباشر ؛ مثل:

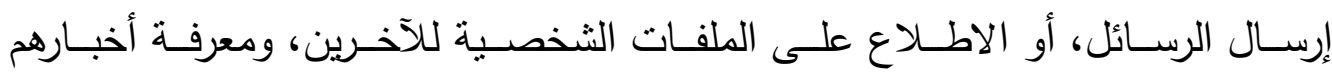
ومعلوماتهم التي يطرحونها للعرض.

وتتنوَّع أثنكال ووسائل التواصل الاجتماعية، فبعضها عام يهدف إلى التواصل العام وتكوين الصداقات حول العالم وبعضها الآخر يتمحور حول تكوين شبكات اجتماعية في نطـاق محدد ومنحصـر في مجال معين مثل شبكات المحترفين وشبكات المصـورين

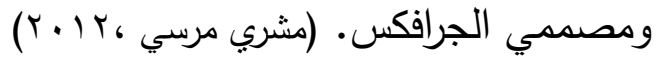

$$
\begin{aligned}
& \text { التطوع الإلكتروني }
\end{aligned}
$$

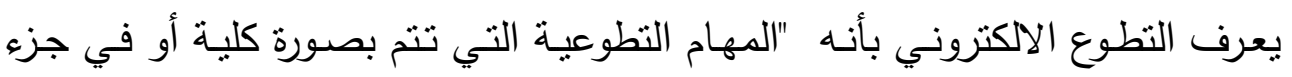

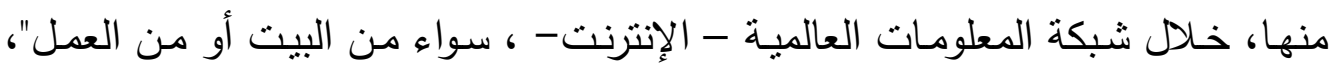

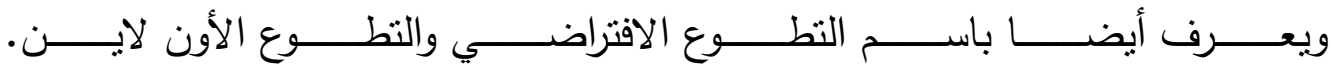
http://www.islamonline.net/Arabic/index.shtml

عينة (الدراسة

تتمنل عينة الدراسة في ( 111) مفردة من الخريجات الجامعيات السعوديات في جامعة

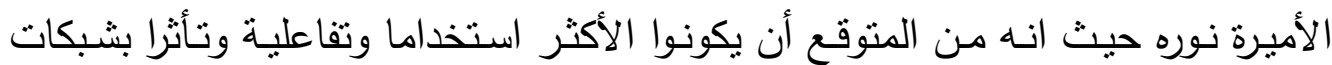

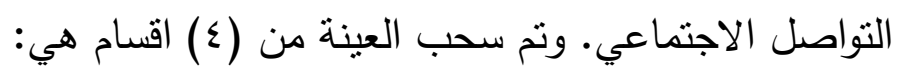
بواقع ( ) ) خريجة لكل قسم بمختلف المعدلات الدراسية حسب نسبتهم • وبناء عليه يطلق على هذا النوع من العينات العينة ذات الأبعاد Dimensional ( الوفائي ،999 (199 ) والجدول رقم (1) يبين خصائص أفراد العينة. 
جدول رقم (1) خصائص أفراد العينة

\begin{tabular}{|c|c|c|c|}
\hline \multicolumn{2}{|c|}{ انثى } & \multirow{2}{*}{ الفئات } & \multirow[t]{2}{*}{ الخصائص } \\
\hline$\%$ & ك & & \\
\hline$\% \leqslant 0, .0$ & Ar & . & \multirow{3}{*}{ 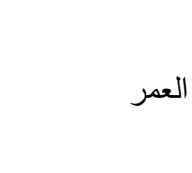 } \\
\hline$\% r V, \Sigma V$ & 0 . & rr- & \\
\hline$\% r V, \varepsilon V$ & o. & اكثر من عr سنة & \\
\hline$r \varepsilon, V r \%$ & $\leqslant 0$ & طفولة مبكره & \multirow{4}{*}{ القسم } \\
\hline$\% r v, \varepsilon v$ & $\leq r$ & تربية خاصة & \\
\hline$\% r v, \varepsilon V$ & o. & علم نفس & \\
\hline$r \varepsilon, V Y \%$ & $\leqslant 0$ & مناهج وطرق تدريس & \\
\hline$r \leqslant, \vee \%$ & $\leqslant 0$ & $r-r, 0$ & \multirow{4}{*}{ المعدل الدراسي } \\
\hline$\%$ \% $\wedge, \circ \mathrm{V}$ & or & $r, 0-r, 1$ & \\
\hline$\%$ r 1, 9V & $\varepsilon$. & $\varepsilon-r, \tau$ & \\
\hline$r \varepsilon, \vee \%$ & $\leq 0$ & $0-\varepsilon, 1$ & \\
\hline
\end{tabular}

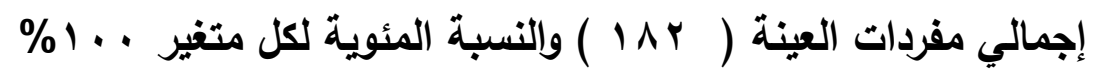

\section{الاطار النظري للاراسة}

\section{أولاً: شبكات التواصل الاجتماعية}

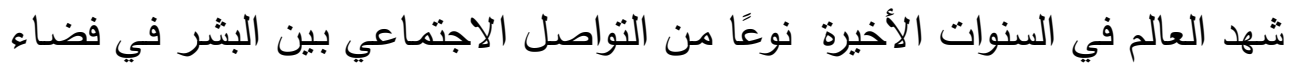

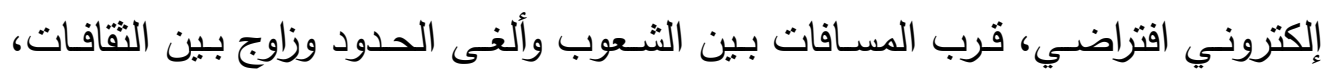
وسمي هذا النوع من التواصل بين الناس شبكات التواصل الاجتماعية وتعددت هذه ولهي الثبكات واستأثرت بجمهور واسع من المتلقين ، ولعبت الأحداث العالمية والطبيعية في لئي

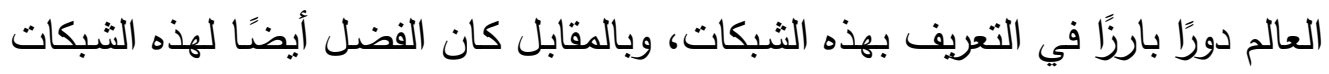

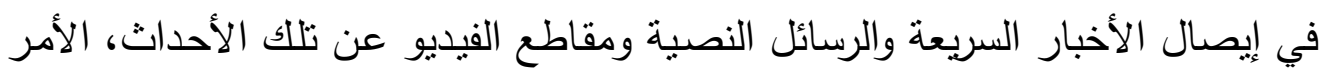

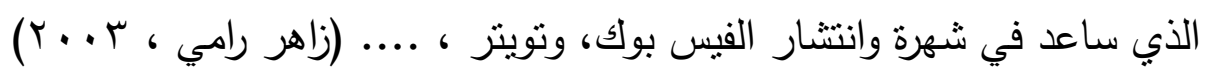

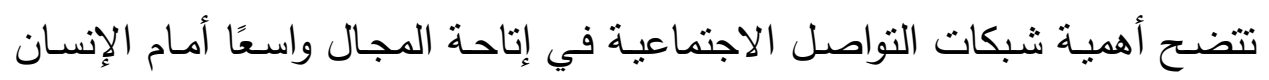

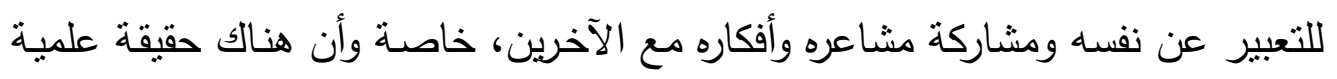




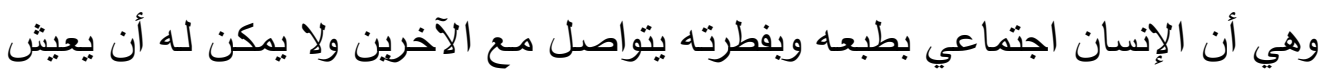

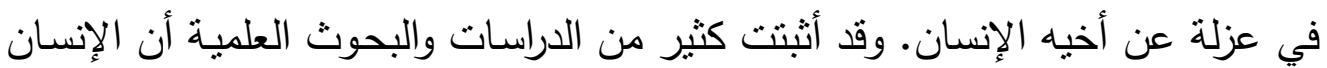

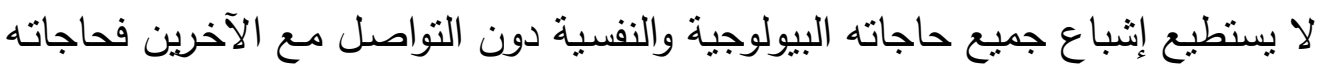
هذه تفرض عليه العيش مع الآخرين لإثشباع هذه الحاجات. أما الاحتياجات الاجتماعية

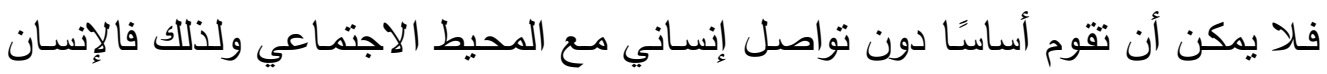
كائن اجتماعي بطبيعته لا يمكن أن يعيش بمفرده.

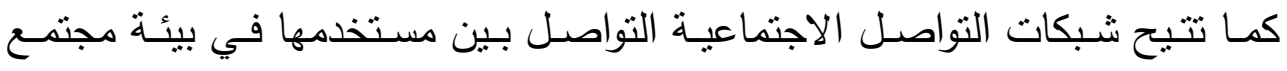

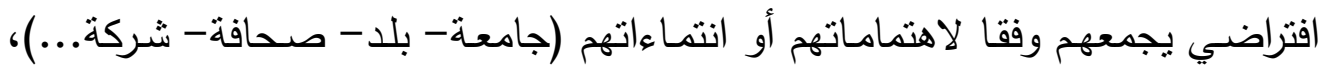
بحيث ينت ذلك عن طريق خدمات التواصل المباشر كإرسال الرسائل أو المشاركة في الملفات الثخصية للآخرين والتعرف على أخبارهم ومعلوماتهم التي يتيحونها للعرض. وتتتوع أنتكال وأهداف تلاك الثبكات الاجتماعية فبعضها عام يهدف إلى التواصل العام وتكوين الصداقات حول العالم وبعضها الأخر يتمحور حول تكوين شبكات اجتماعية في نطاق محدود ومنحصر في مجال معين مثل شبكات المحترفين وشبكات المصورين وشبكات الإعلاميين ، بحيث يصبح الثخص في هذا المجتمع عضو فاعل، أبي أنها يرسل ويستقبل ويقرأ ويكتب ويشارك، ويسمع ويتحدث، فدوره هنا تجاوز الدور السلبي

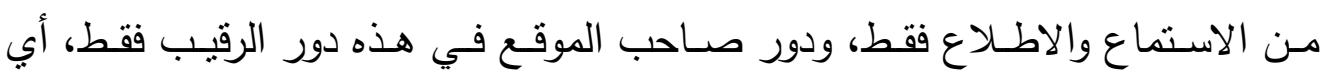

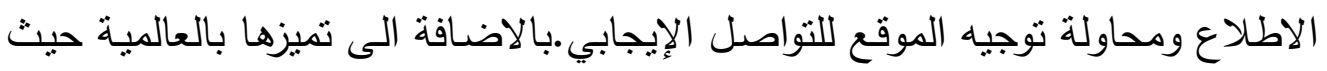

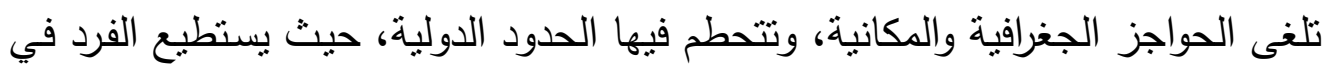
الثرق التواصل مع الفرد في الغرب، .

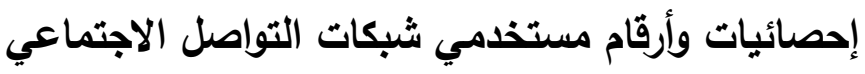

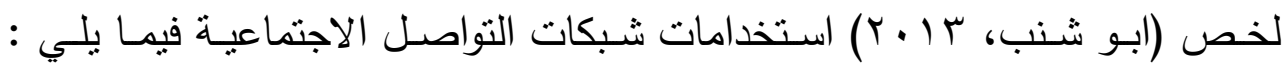
الاستخدامات الاتصالية الثخصية. وهو الاستخدام الأكثر شيوعًا، ولعل الثرارة الأولى للشبكات الاجتماعية اليوم كانت بهدف التواصل الثخصي بين الأصدقاء في منطقة معينة أو مجتمع معين، وهذا الهدف 
موجود حتى الآن برغم تطور الثبكات الاجتماعية على مسنوى الخدمات وعلى مستوى التقنيات والبرمجيات، وبرغم خروجها من حدود الدولة إلى فسيح جو العالم.

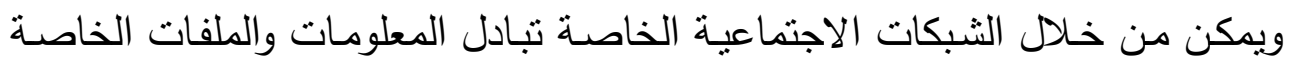

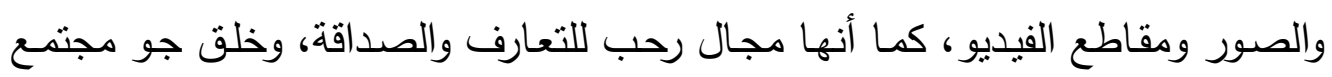

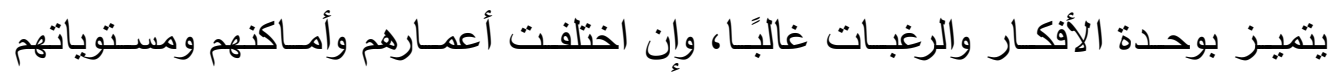
العلمية.

\section{الاستخدامات التعليمة:}

إن الدور الذي تلعبه الثبكات الاجتماعية في تطوير التعليم الإلكتروني حيث تعمل

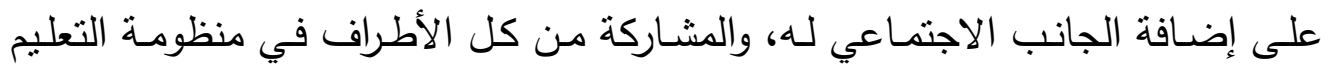
بداية من مدير المدرسة والمعلم وأولياء الأمور وعدم الاقتصار على التركيز على تقديم المقرر للطلاب. - من ملايز

فاسـتخدام الثـبكات الاجتماعيـة يزيــــــرص النواصـل والاتصــال في خـارج نطـاق الددارس، ويكسر حاجز الوقت فيمكن التواصل خارج وقت الدراسة، ويقضي على كثير

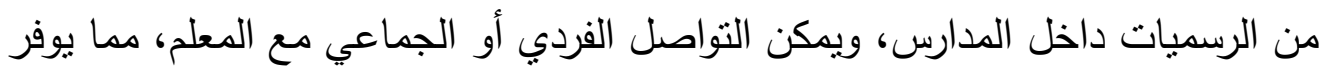

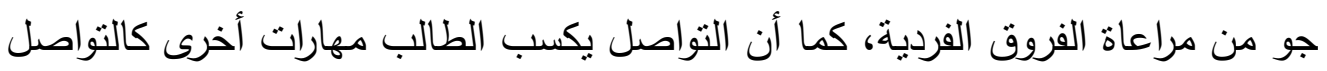

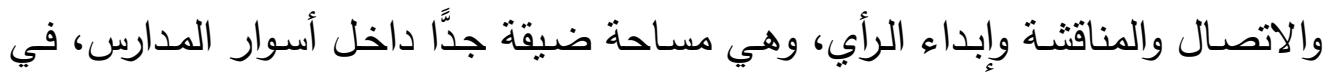

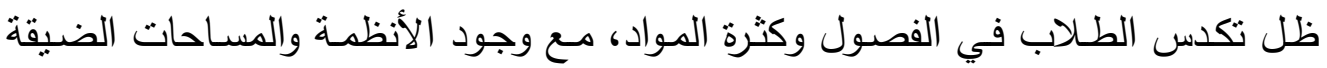
للمناقنتات والتداولات.

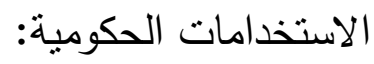

اتجهت كثير من الدوائر الحكومية للتواصل مع الجمهور من خـلال مواقع التواصل الاجتماعي، بهدف قياس وتطوير الخدمات الحكومية لديها، ومسايرة للتقنية الحديثة، بل مركل

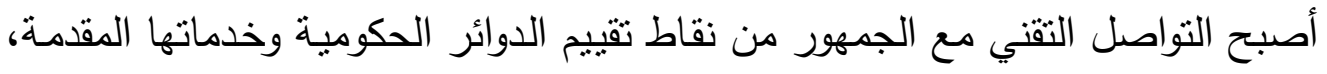

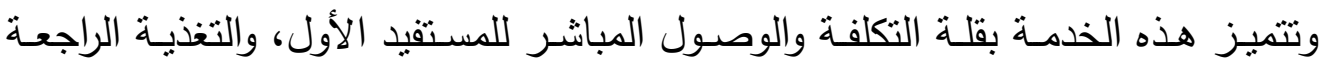
المباشرة، مما يساعد في تفادي الأخطاء والوصول بالخدمة المقدمة للإتقان والتميز . 
كمـايمكن الاسـتفادة مـن الثـبكات الاجتماعيـة في حجز المواعيد وتأكيدها، ونشـر التعليمات والإجراءات، والنواصل مع الرئيس مباشرة، وإبداء الملاحظات والمقترحات.

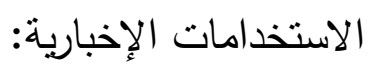

أصبحت الثبكات الاجتماعية مصدر أصيل من مصادر الأخبار لكثير من روادها،

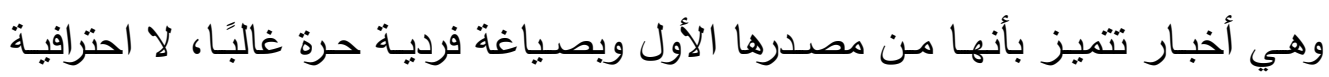
لاستخدامات مختلفة سياسية أو دعائية. وقد تميزت المدونات الخاصـة باسـتقطاب البـاحثين عن الأخبـار ، ومواقـع الأخبـار المتخصصة، وقنوات إخبارية كبيرة، في أحداث مختلفة سابقة، وكان لأصحابها التأثثر الكبير في نقل الأخبار الصحيحة للرأي العام. الاستخدامات الدعوية. فتحت الثبكات الاجتماعية الباب للتواصل واللدعوة مـع الآخرين مسلمين أو غير مسلمين باختلاف لغاتهم واختلاف أجناسهم وبلدانهم، وأصبح لكثير من الدعاة صفحاتهم

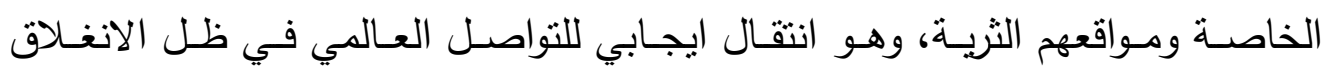
الإعلامي الرسمي في كثير من الدول، وفي ظل أنظمة تعيق التواصل المباشر وتثقبل

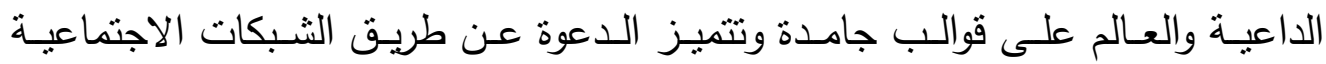

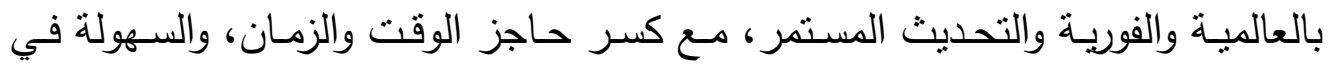
الاستخدام والتواصل، والتوفير في الجهد والتكاليف (غسان، الدقدادي، بات ـ ب). توصيات للاستفادة من وسائل التواصل الاجتماعية ولتية

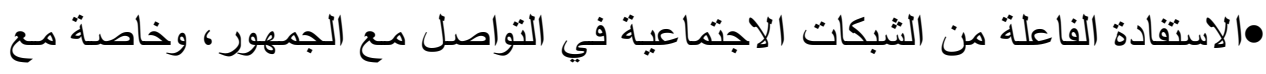
جيل التقنية شباب الغد. •تركيز المؤسسات الأهلية والثبابية على تدريب الثباب وتزويدهم بالمهارات اللازمة لاستخدام وسائل الإعلام الجديد. 


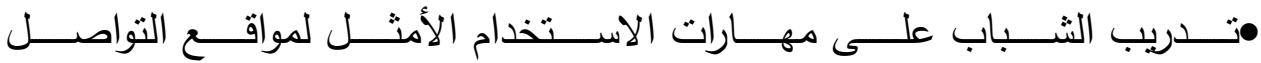

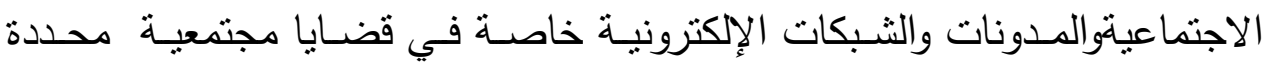
للتعميق الثبابي ل •إجراء دراسات على مجتمعات مختلفة منها مجتمع طلبة الجامعات والأطفال وطلبة المراحل الأساسـية في المـارس، وفحص مـدى تـأثير اسـتخدام مواقـع التواصـل الاجتماعيةفي تتمية المسئولية الاجتماعية.

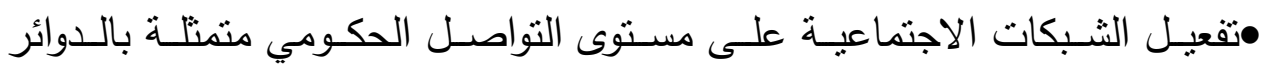
الحكومية والخدمات الحكومية، مع المجتمع المتمنتلة في المستقيد والجمهور العام. •أهميـة التأكيد على ضـرورة توجيه الآبـاء لأبنائهم وإرشـادهم بالاستخدام الصحيح للإنترنت لحمايته بواسطة برامج التصفح التي تسمح بتصفح الانترنت بصورة آمنة

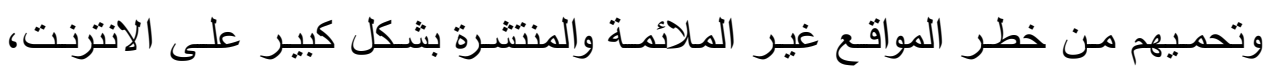

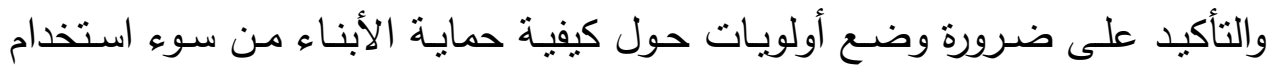

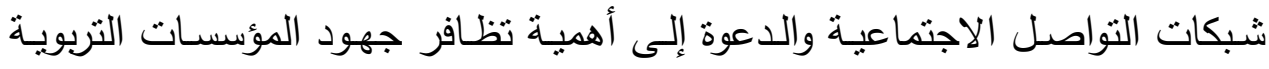

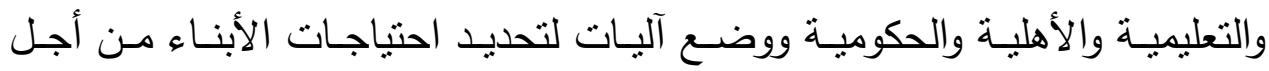
الوصول للاستخدام الأمتل من قبلهم لثبكات التواصل الاجتماعية . العمل التطوعي الإكتروني

يعد العمل التطوعي وحجم الانخراط فيه رمزاً من رموز نقدم الأمم وازدهارها، فالأمة كلما ازدادت في التقدم والرقي، ازداد انخراط مواطنيها في أعمال التطوع الخيري. كما لهم

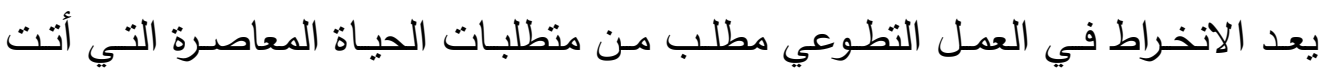
بالتتمية والتطور السريع في كافة المجالات.

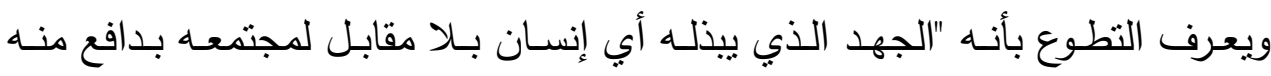

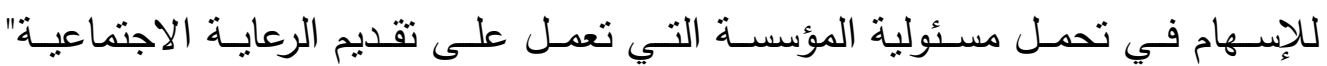

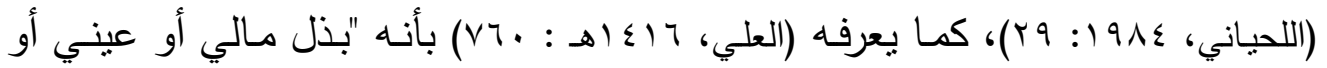


بدني أو فكري يقدمـه المسلم عن رضـا وقناعـة، بـدافع مـن دينه، بدون مقابل بقصد الإسهام في مصالح معتبرة شرعاً، يحتاج إليها قطاع من المسلمين".

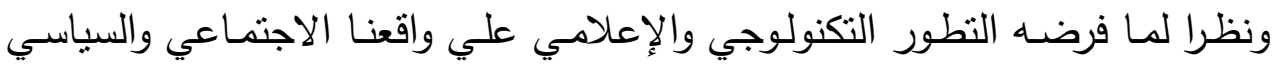

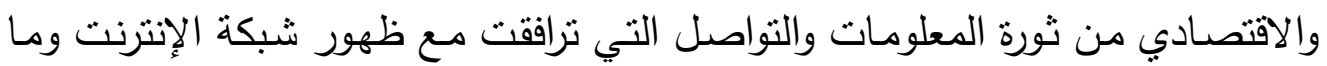

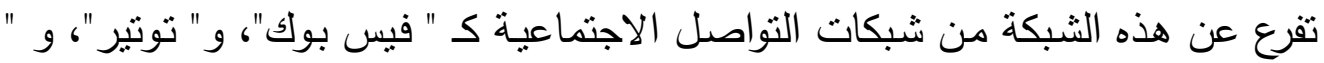
يوتيوب"، وغيرهـا من مواقع التواصل الاجتماعية التي يتجاوز عدد مستخدمي الواحد

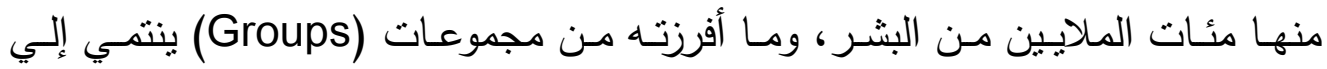

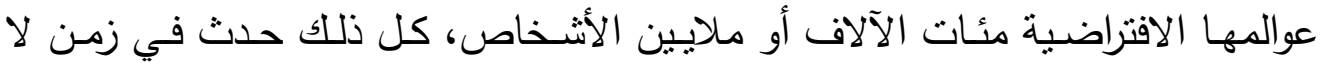

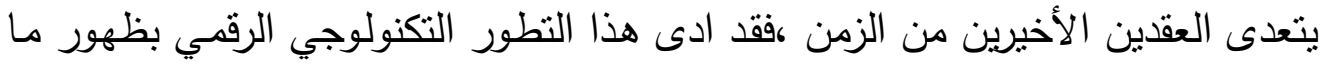

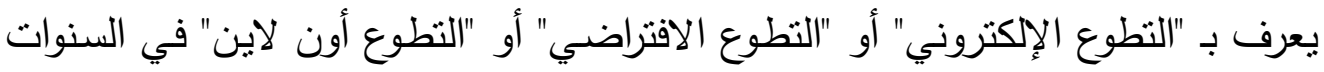

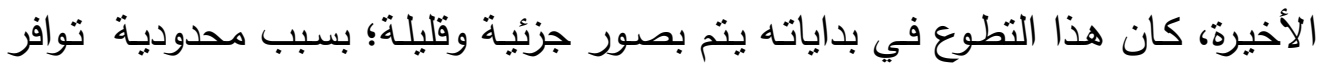

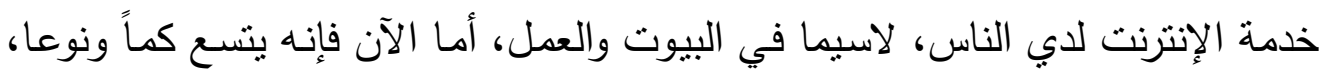
وربما تمدد وبنسب معتبرة علي حساب التطوع الميداني والذي يتم علي أرض الواقع.

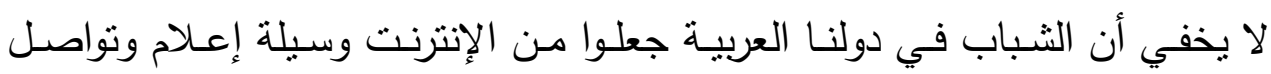

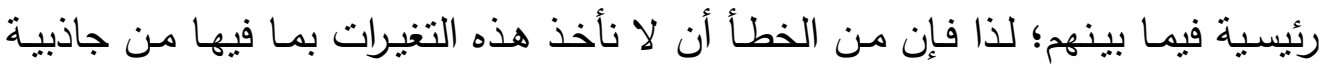

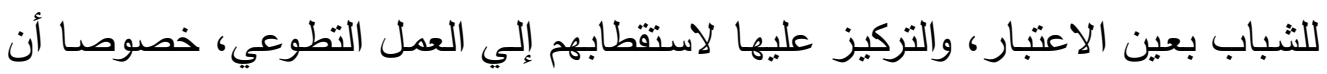
ثمـة إحصـاءات تثـير إلي تضـاعف عدد المستخدمين للإنترنت باللغـة العربيـة بنسبة

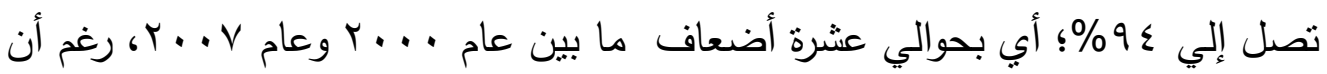

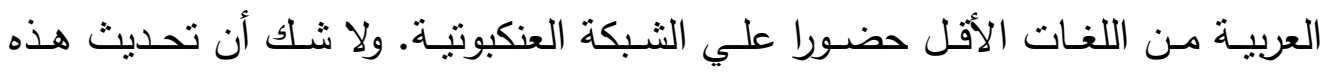
الإحصاءات سيكثف عن مزيد من الحقائق المذهلة، خصوصا ما يتعلق باتساع آفاق

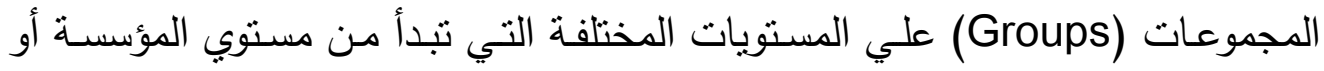

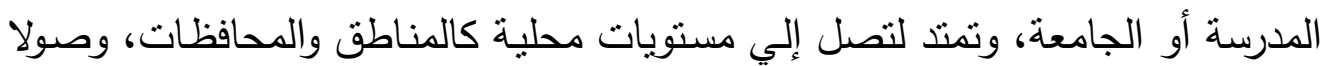

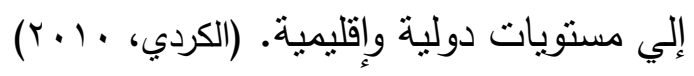


وقد لعبت شبكات التواصل الاجتماعية دورا كبيرا في دعم العملية التطوعيـة

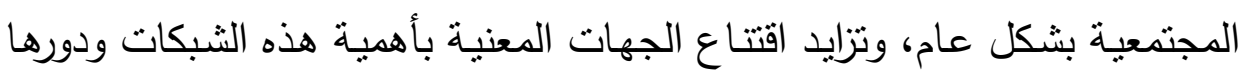

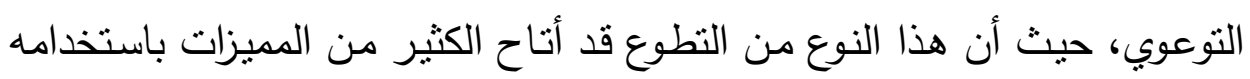

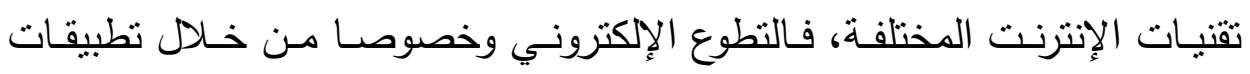
الهواتق المحمولة يوفر فرصة للوصول لقدر أكبر من المجتمع لم نكن لنصل إليه

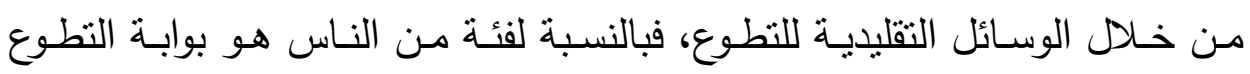

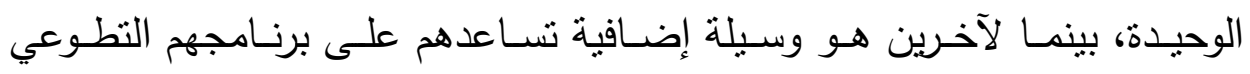

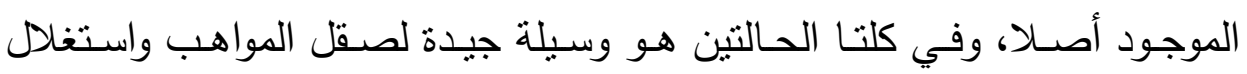
الوقت، ولا يخفى أن الثباب في دولنا العربية جعلوا من الإنترنت وسيلة إعلام

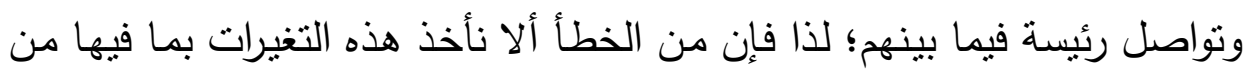

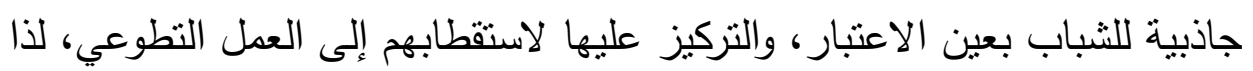

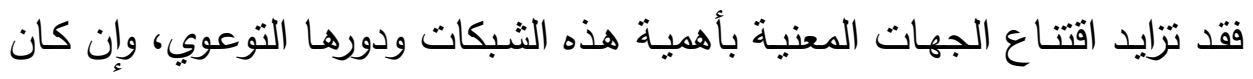
الأمر ما زال بحاجة إلى مزيد من الاهتمام والعناية لمواكبة التطورات المتسارعة.

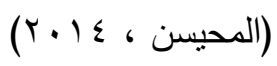

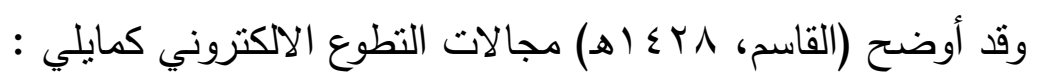

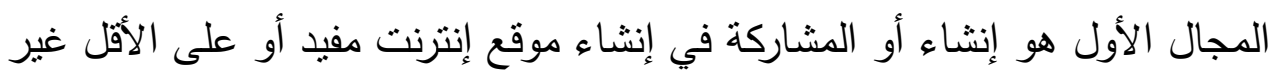

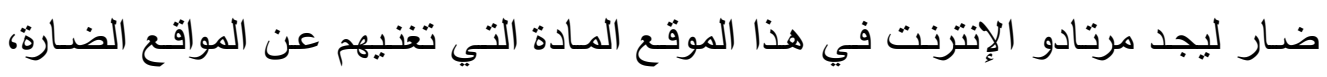

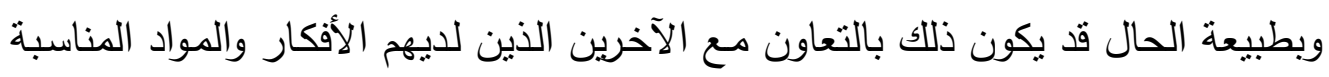

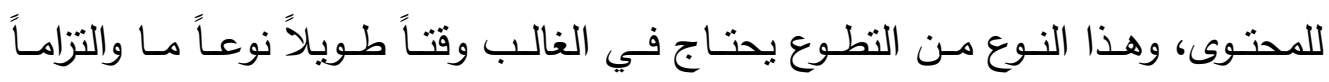

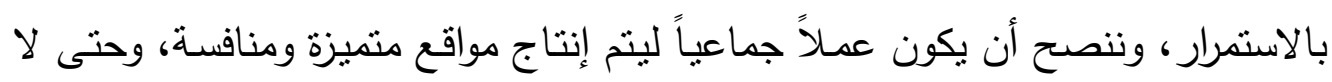

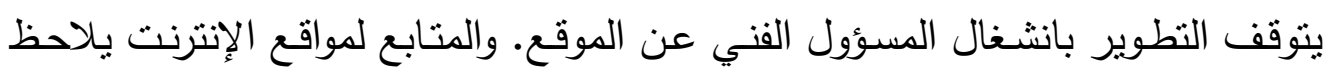

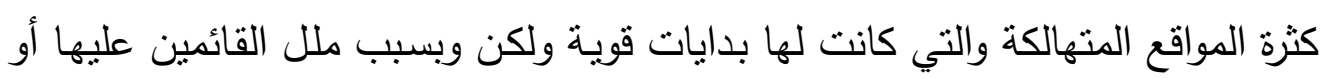
انشغالهم تهمل هذه المواقع. 
المجال الثاني هو المشاركة في التدريب في مجال تقنية المعلومات وذلك بالتعاون

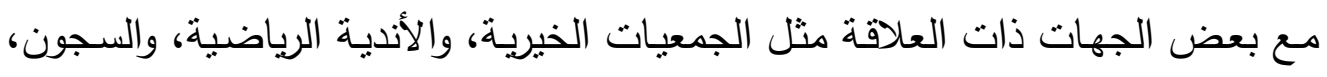
وغيرها من الجهات، وهذا يتطلب التقيد بأوقات معينة والذهاب لأمساكن التدريب، ويتميز هذا العمل بالاحتكالك المباشر بالآخرين وتوصيل مهارات تقنية مفيدة لهذه الفئة الغالية

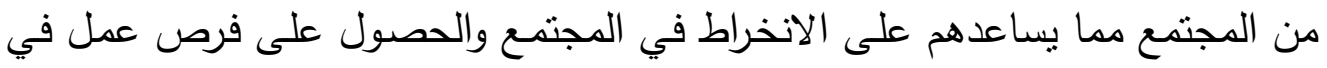

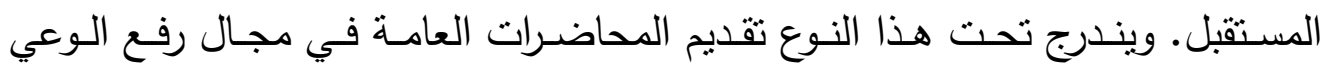

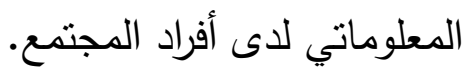
المجـال الثالث هـو مسـاعدة الجهات غير الربحيـة كالجمعيـات الخيريـة والمسـاجد والأندية الرياضية في مجالات ذات علاقة بتقنية المعلومات، كتصميم مواقع الإنترنت أو لونيك

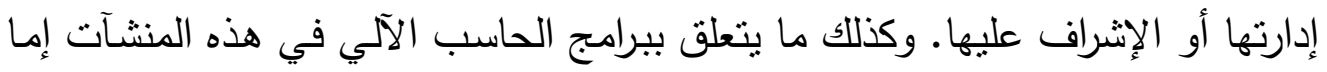

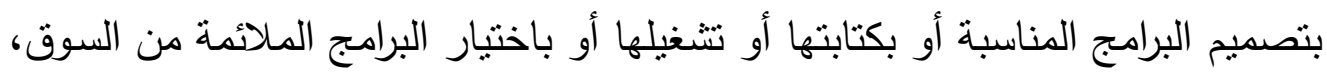

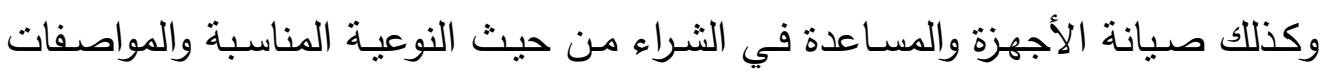
المطلوبة. وهناك العديد من الجهات التي يكفيها ساعات قليلة في الأسبوع. التطوع الإلكتروني يعد هو مستقبل العمل التطوعي و ذللك للأسباب متعددة و مختلفة حيث ان معظم مؤسسات العمل التطوعي العالمية اليوم تقوم بالتواصل مـع المنطوعين

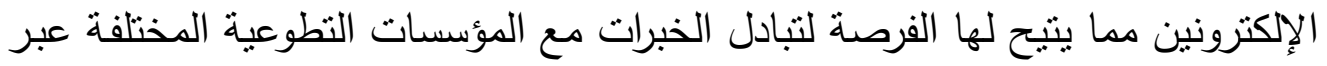

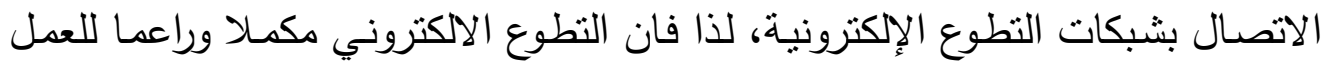
التطوعي الميداني حيث يمكن المتطوع عبر وسائط الاتصال الالكتروني من تحقيق ماقد الإندانه يعجز عنه المتطوع الميداني. التطوع الإلكتروني يمتلك القدرة علي تسخير مهارات و كفاءات تطوعية بارزة عن

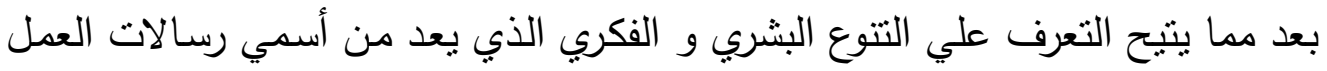

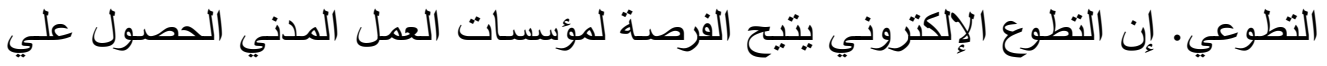

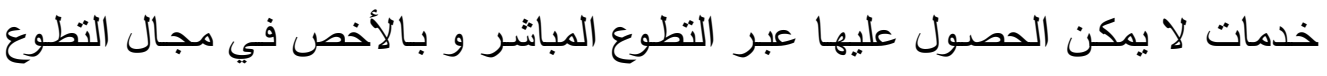

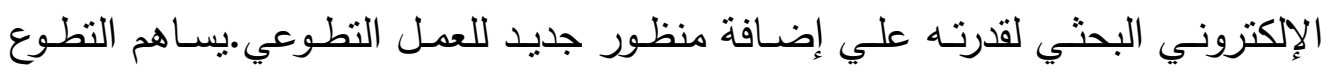


الإلكترونـي بـإثراء تجربـة العمل التطوعي وربط المشـاريع التطوعيـة بـالجهود العالميـة

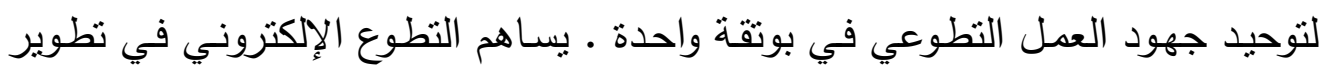

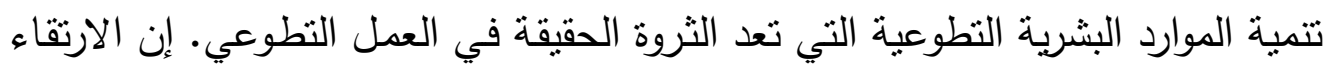

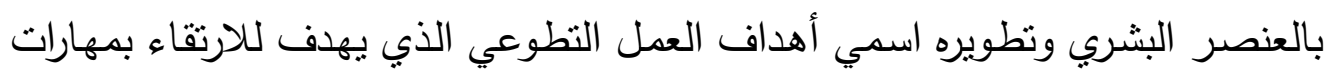

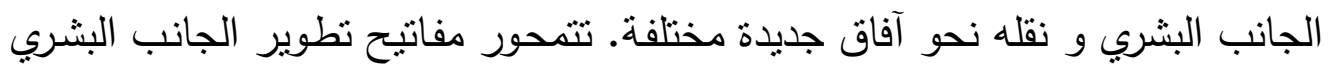

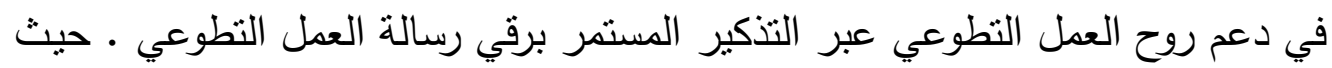

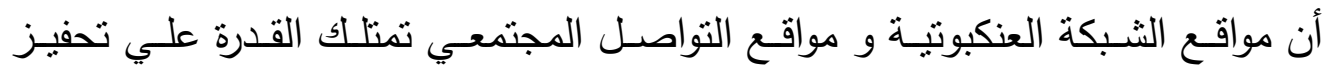

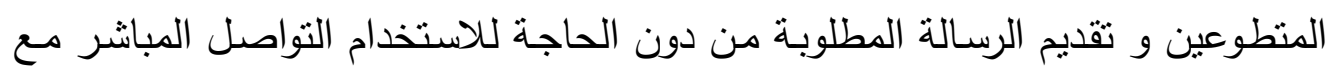

$$
\text { المتطوعين. (نزال وحبش، } 10 \text { • ب). }
$$

بسـهم التطوع الإلكترونسي في تطوير مهارات التواصل عبر تبـادل الآراء و طرح

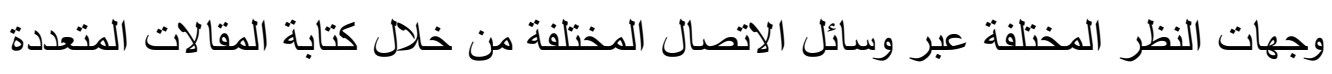
و التقارير التي تناهم في تطوير العمل التطوعي و نقل إرث العمل التطوعي للأجيال

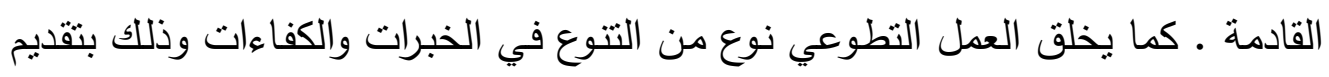
وجهات نظر مختلفة تتبع مـن اختلاف البيئات والأعراق والخلفيات التي يقدم منهـا المتطوعين. أما في جانب تطوير مشاريع العمل التطوعي العامة يتيح التطوع الإلكتروني لقادة

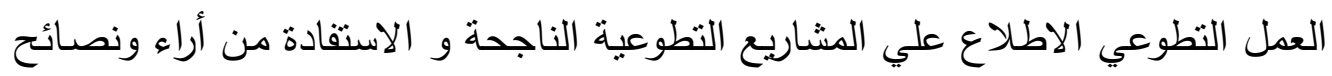

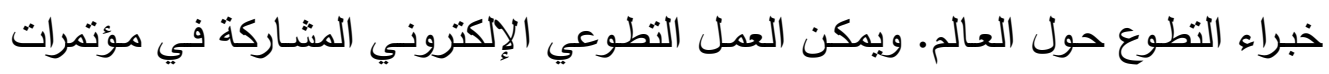

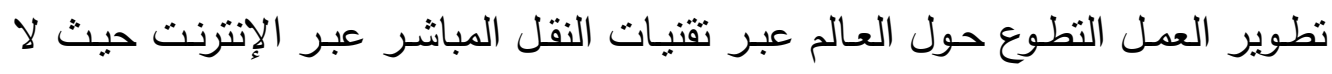
تقتصر المشاركة علي المشاهدة بل التفاعل المباشر مع بيئة المؤتمرات و طرح و تبادل الآراء المختلفة.

ويساهم العمل التطوعي الإلكتروني في تطوير العمل التطوعي عبر تقسيم المهام

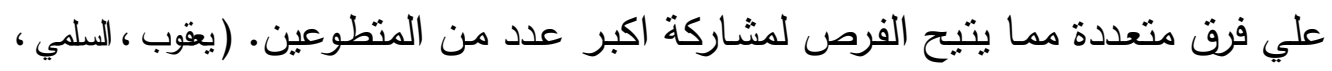

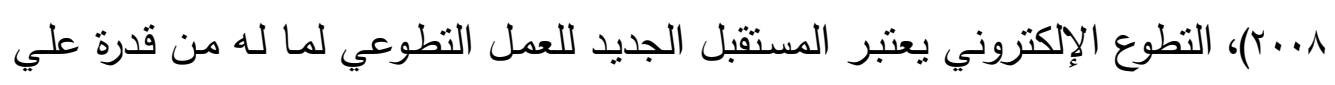


الوصول للآفاق جديدة و تطوير المؤسسات التطوعية الصغيرة من دون الحاجة لتركيز

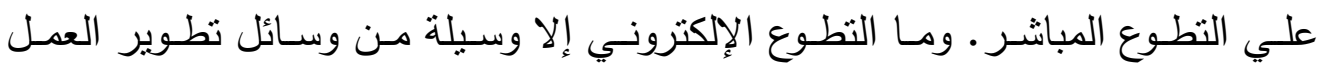

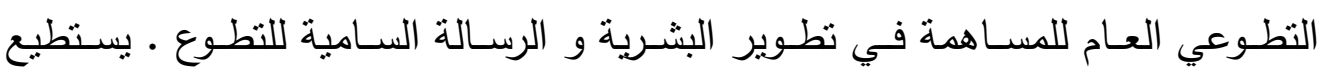

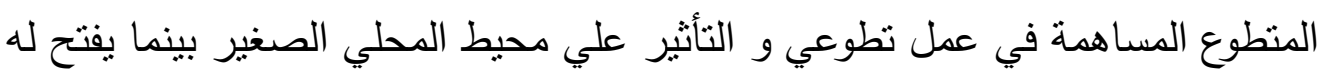
التطوع الإلكتروني باب الانطلاق للعالمية و المساهمة في نهضئة الإنسانية و أجيال المستقبل. من الأمتلـة العملية المهمة في هذا المجال إطلاق نـاد نطوعي إلكتروني بالمملكة

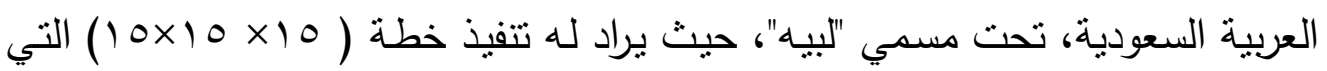

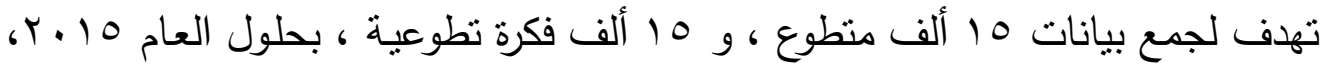

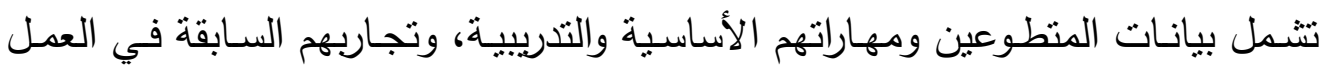
التطوعي، وفق استراتيجية مدروسة لتنظيم العمل التطوعي، وإيجاد قاعدة بيانات حقيقية ومنظمة، وسد ثغرة العشوائية في بعض الجهود التطوعية عند حدوث الأزمات والكوارث.

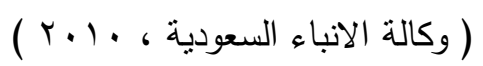
وعلي موقع " فيس بوك". ومثل ذللك في المواقع المشابهة ـ . تجد آلاف المجموعات

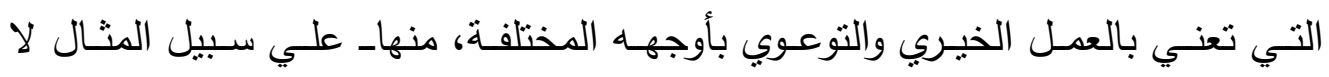

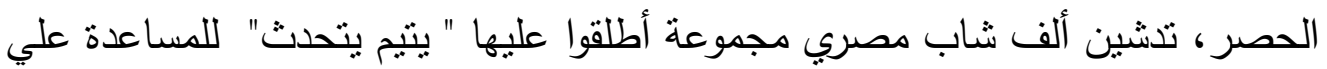
كفالة أكبر عدد مدكن من الأيتام، وتحت شعار "بلسان العديد نتحدث. وبعيون الكثير نري. بيد المسكين نتودد. وبدموع الطفل بنقوي"، انطلقت مجموعة "قلوب سودانية نابضة ولابة

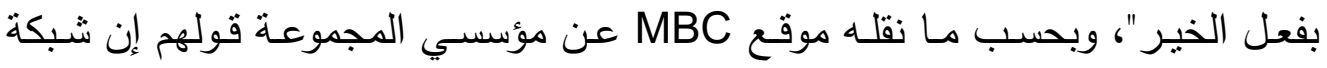

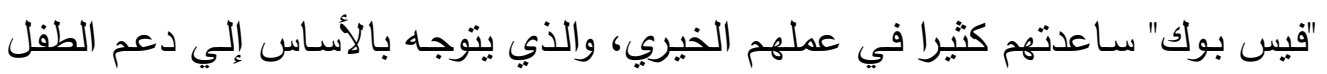

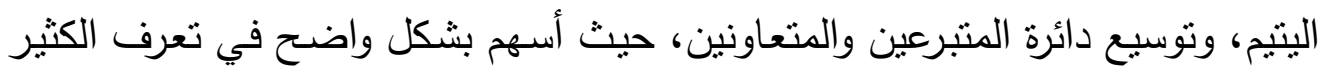
من رجال الخير علي المجموعة التي صسارت تعتمد علي تبرعاتهم. ومن المؤكد أن أن

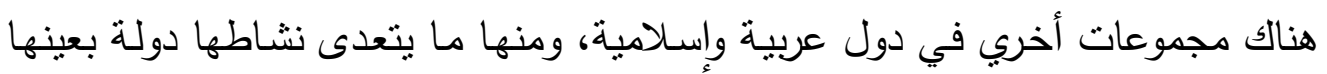
ليتسع لكل الدول الخليجية، أو للعالم العربي بأكمله، أو للعالم بأسره (ورقلة، نادية با. • ب). 
الملايين المهم فهم هذه الأجواء وكيفية استتمارها في الأمور الإيجابيـة إذا أردنا

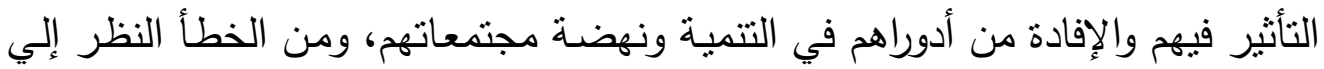

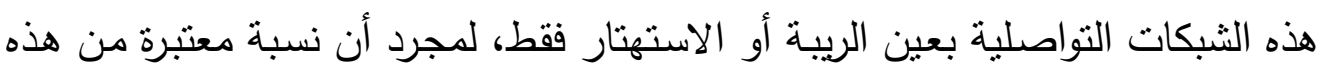

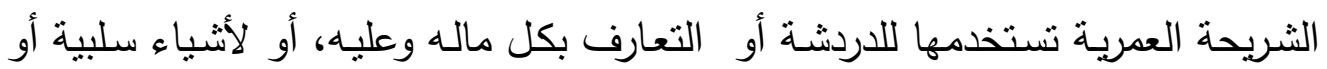
مؤذية.

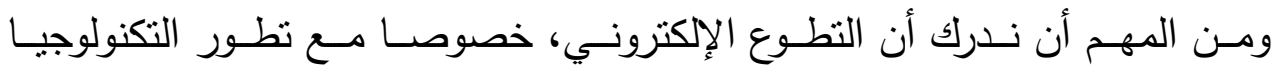
الاتصالية الهائل، يكمّل التطوع الميداني ويدعم وظائفه، وقد يتمكن المتطوع الإكتروني

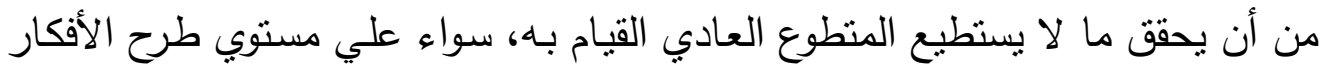

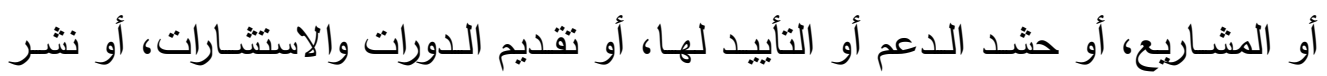
الخير وتعميمه... وفي كلٍ خير. نظرا لعدة عوامل - لعل أهمها عدم توفر الوقت بالنسبة لبعض الناس - ظهرت فكرة التطوع الإكتروني أو الافتراضي، ولا يزال هذا المصطلح غريبا علي مجتمعاتتا العربية،

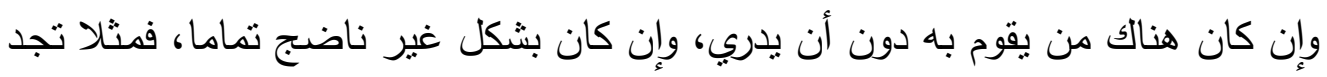

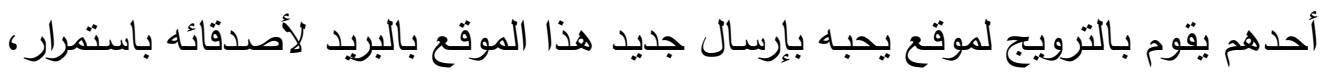

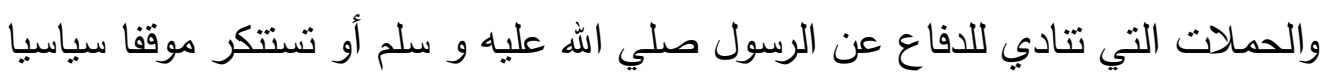
لأحد الحكومات، وهناك الكثير من الأمثلة الأخرى.

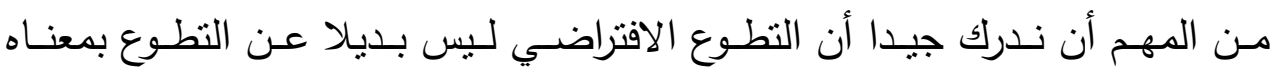

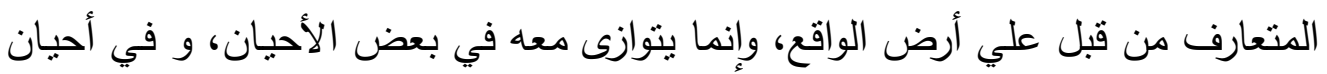

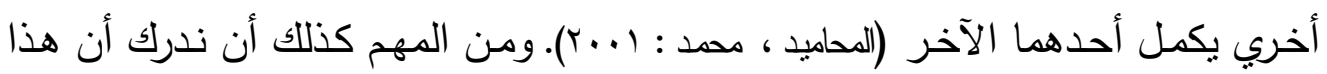

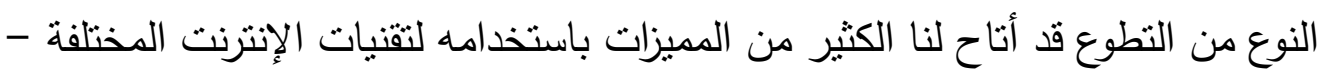

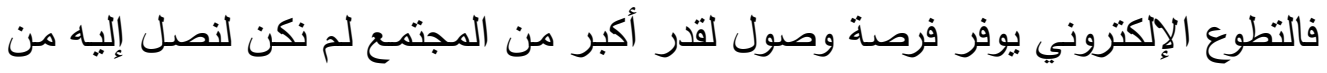
خلال الوسائل التقليدية للنطوع، فبالنسبة لفئة من الناس هو هورئ بوابة التطوع الوحيدة، بينما لآخرين هو وسيلة إضافية تساعدهم علي برنامجه التطوعي الموجود أصلا، وفي كلا

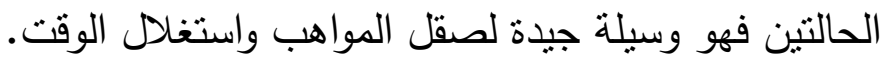




\section{ما أهمية التطوع الإكتروني؟}

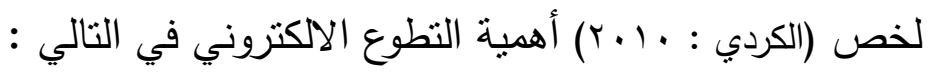

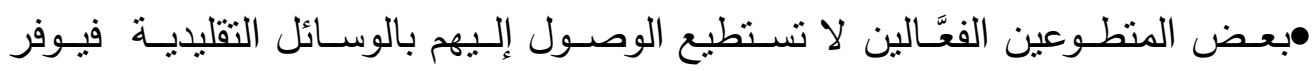

الإنترنت وسيلة التواصل معهم.

•يوجد بين الناس من لا يحب العمل علي أرض الواقع لما يشمله ذلك من الكثير من

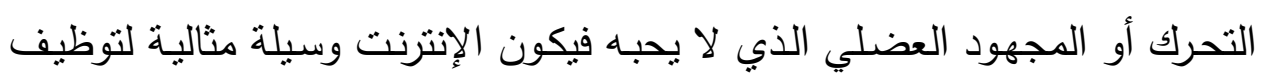

هؤلاء.

•يتيح الأون لاين فرصـة لمن يريد الاشتراك أن يعيد تقييم نفسه ومهاراته قبل التقدم

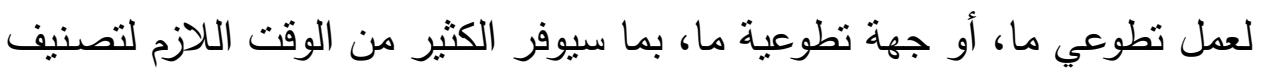

مهارات المتطوع و توظيفها في الاتجاه الصحيح. •بعض المتطوعين كذلك يحبون التواصل علي الأون لاين، أو إرسال بريد إلكتروني، أو ملء استمارة تشجيل عن هواياته المفضلة. •هناك بعض الحالات الإنسانية التي تمنع محبي التطوع من التطوع التقليدي، مثل

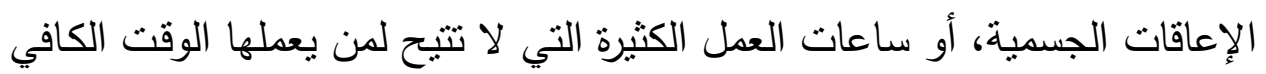

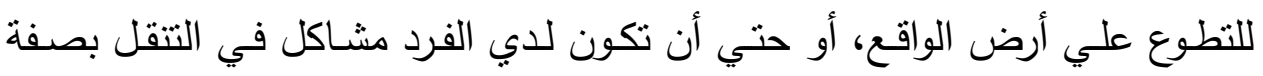
عامة. •المتطوعون عبر الإنترنت هم أصدقاء أكثر للبيئة، فهم لا يستهلكون الوقود، وليس لايهم أية فضلات من الورق ناتجة عن عملهم ... إلخ.

الدراسات السابقة أولا: الدراسات المتعلقة بمواقع التواصل الاجتماعي: هنالك عدة دراسات تطرقت لأثر استخدام مواقع التواصل الاجتماعية "الفيس بوك "

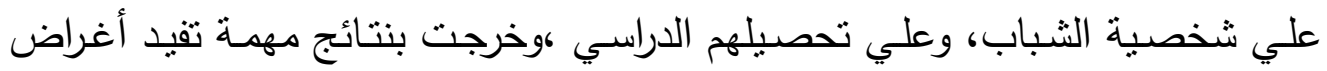
الدراسة الحالية، وفيمايلي عرض موجز لبعض الدراسات التي تتاولت موضوع الدراسة: دراسة أرين كار بنسكي (2010- Aren karbnsky) 
هدفت للتعرف إلي أثز استخدام موقع "فيس بوك" علي التحصيل الدراسي لدي طلبة

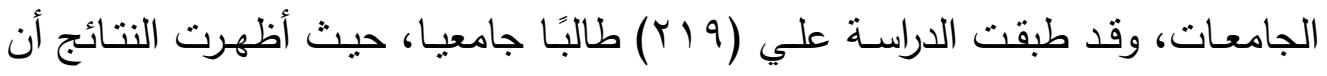
الدرجات التي يحصل عليها طلاب الجامعات المدم نون علي شبكة الانترنت وتصفح

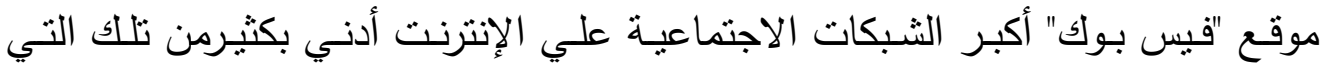

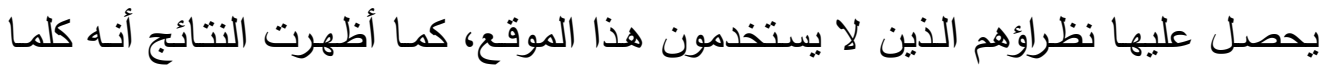

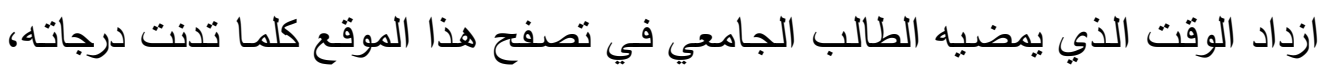

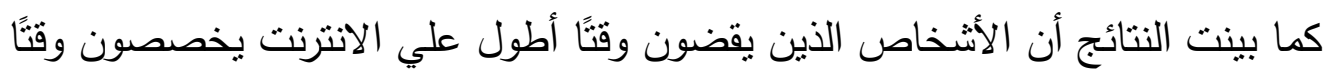

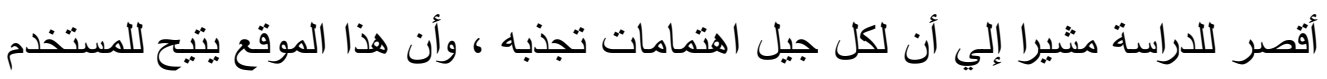

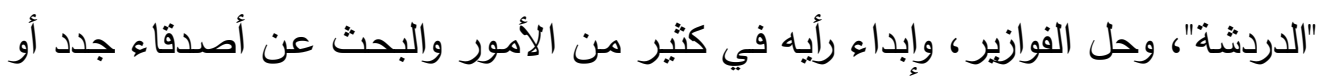

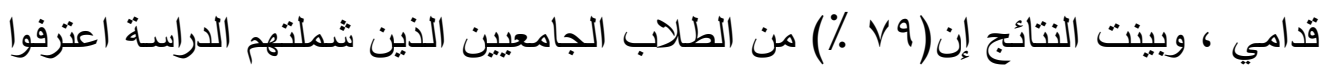
بأن إدمانهم علي موقع "الفيس بوك" أثزّز سلبيًا علي تحصبلهم الدراسي.

الى التعرف علي أثر استخدام شبكات (Meshel,2010) كما هدفت دراسة ميشيل

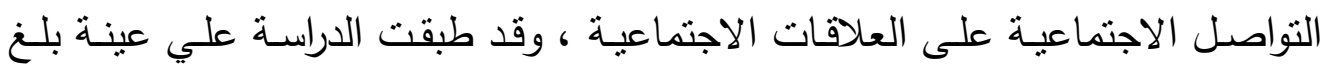

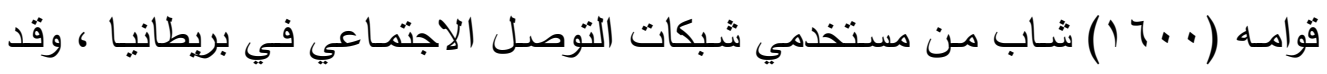
أظهرت النتائج أنَّ أكثر من نصف الأشخاص البالغين الذين يستخدمون مواقع من بينها

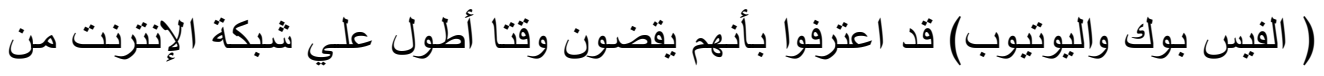

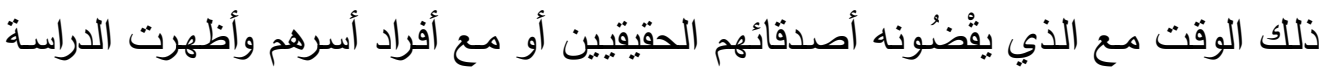
أيضا أنهم يتحدثون بصورة أقل عبر الهاتق ، ولا يشاهدون التلفاز كثيرًا، ويلعبون عددا أقل من ألعاب الكمبيوتر ، وبرسلون كمية من الرسائل النصية وكذلك البريدية وقد بينت

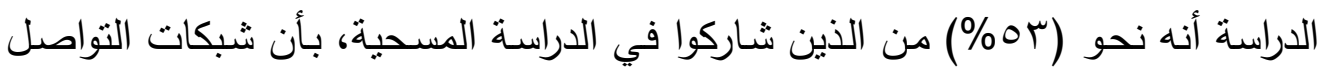

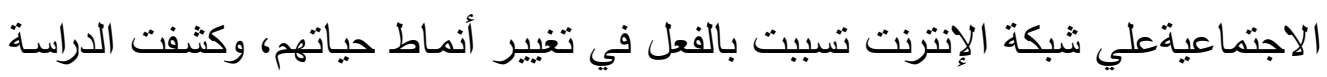

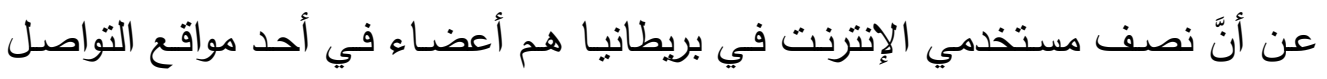

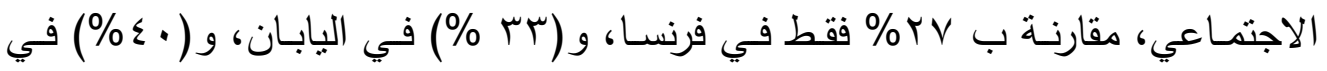

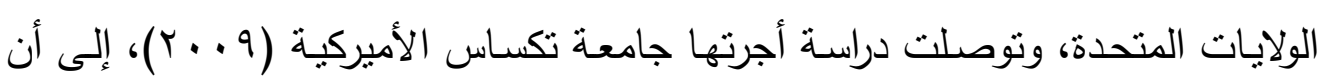


الناس يقبلون علي استخدام مواقع التواصل الاجتماعية وعلى رأسها موقع "فيس بوك"

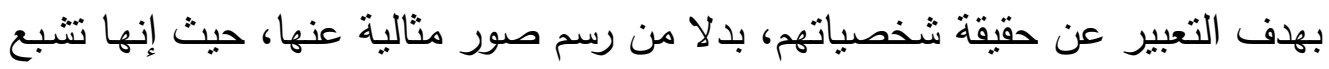

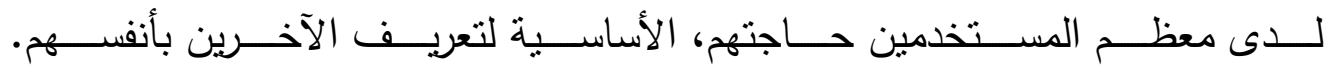
(http://almokafa.ahlamontada.com/t135-topic)

كما بينت دراسة العتيبي (^ . . ب) التي هدفت للتعرف علي تأثير الفيس بوك علي طلبة الجامعات السعودية، أن نسبة انتشار استخدام "الفيس بوك" بين طلاب الجامعات

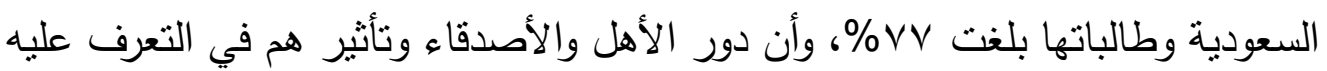

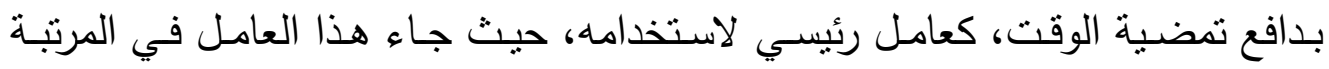

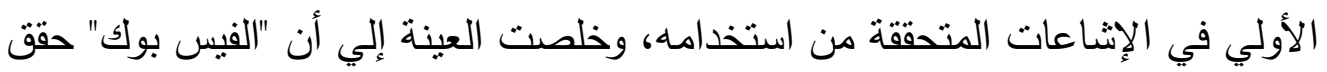

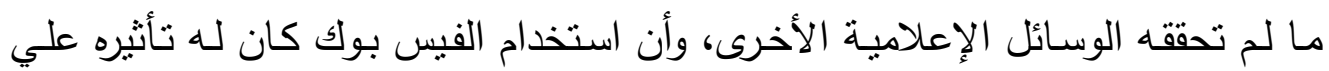
الثخصية أكثر من الوسائل الإعلاميةالأخرى .

.(http://www.otaibah.net/m/showthread.php?p=1175673)

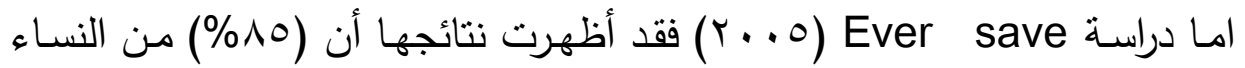
يتعرضن لمضايقات على الفيس بوك، كما أظهرت النتائج كذلك أن (•^\%) من النساء تأثنرن بعادات المستخدمات على الفيس بوك وتجاربهن، وأن (10\%) من النساء اللواتي

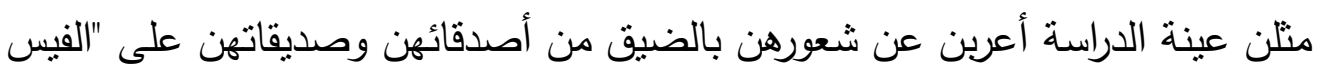
بوك"، وتعددت أوجه الضيق وتفاوتت بالنسبة لكل منهن، فجاءت الثكوى على الدئ الدوام كأحد أكثر الأمور التي تزعج المستخدمات علي الفيس بوك من صديقاتهم وأصدقائهر

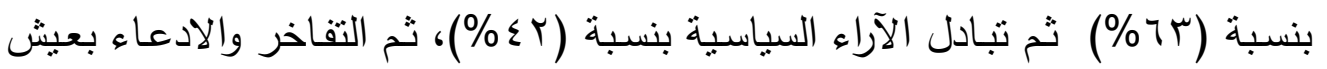

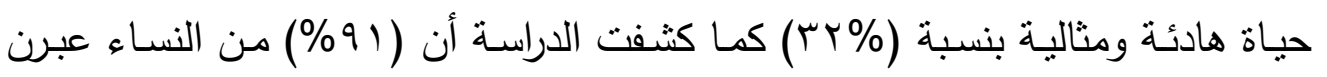
عن تقديرهن الكبير للادور الاجتماعي الكبير الذي يلعبه الفيس بوك في حياتهن وتحديدًا

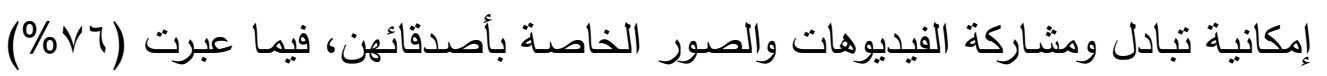
من هؤلاء بالإعجاب بقدرة "الفيس بوك" على لم شـمل الأصدقاء وبخاصـة الذين لم يتقابلوا أو يجتمعوا منذ مدة طويلة.(http://www.aitnews.com/news/14468.html). 
دراسة بعنوان الطـلاب والثبكـات الاجتماعية مع النطبيق علي عينة من طلبة كلية الفنون والاعلام بجامعة الفاتح في ليبيا لمستخدمين للفيس بوك كثبكة بهدف البحث

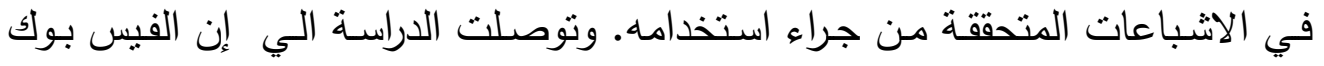
كثبكة اجتماعية يستخدم من معظم الطلبة وهم من يخبرون بعض عنه ،وان السبب

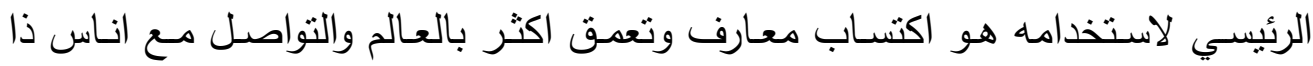

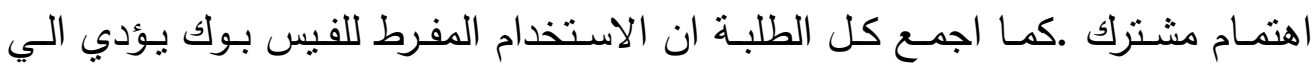

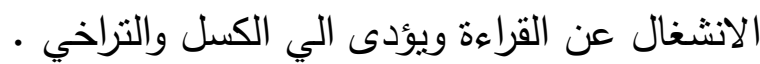

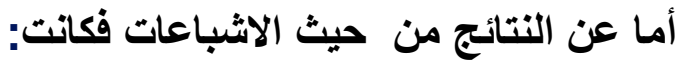

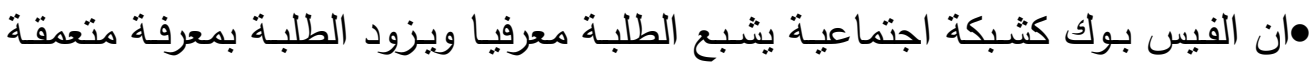
بالعالم •للفيس بوك اشباع اجتماعي حيث انه يخلق جو اجتماعي وتواصل بين الزملاء حتي في اوقات العطلات •للفيس بوك اثشباع فكري حيث انه طرح افكار جديدة للتواصل بين الطلبة ويناقشون مع

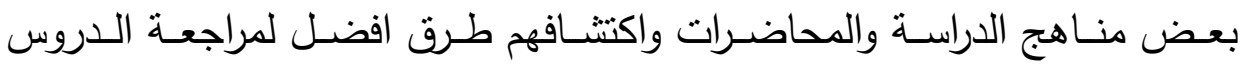

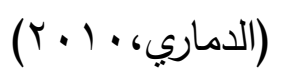

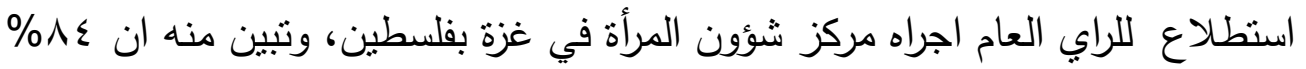
من المبحوثين لديهم حساب في احدي شبكات التواصل الاجنماعيةحيث بلغت نسبة

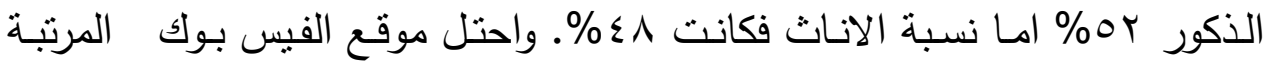

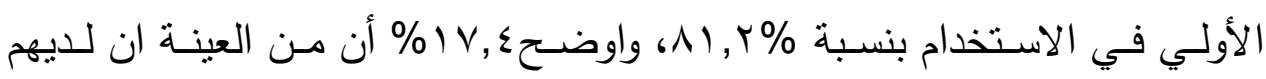
حساب علي اليوتيوب(You Tube) كذلك صرح \%,9\% من عينة الاستطلاع وجود

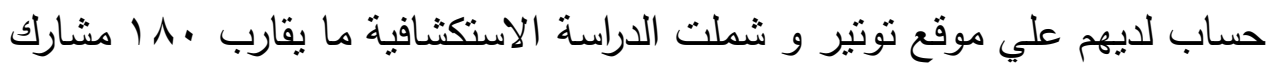
من مختلف فئات المجتمع شملت الذكور والإنات وتضمنت جهات مختلفة مثل ماتل القطاع الخاص والمنظمات الأهلية والمنظمات الحقوقية والنسوية، النقابات المهنية،

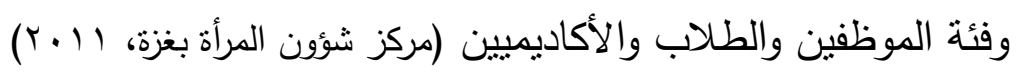


- دراسة نرمين خضرحول الآثار النفسية والاجتماعية لاستخدام الثباب المصري لمواقع

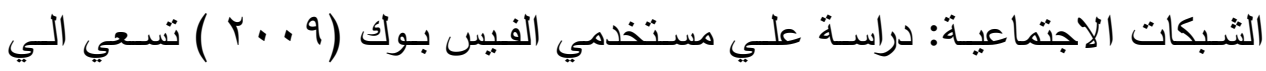

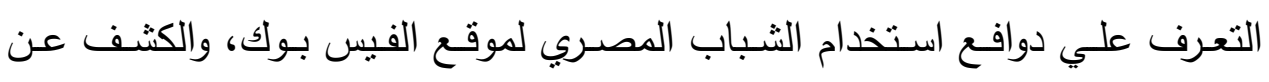

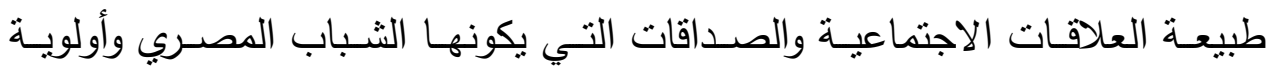

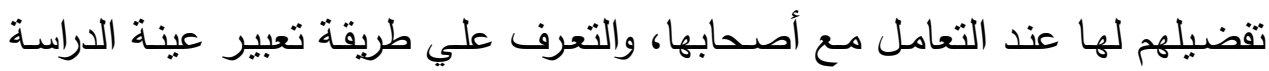
عن حالتهم النفسية والاجتماعية من خلال استخدامهم موقع الفيس بوك. وكان من

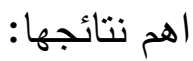
( ) - أن أبرز مصادر معرفة طلبة جامعة القاهرة والجامعة البريطانية بموقع الفيس بوك

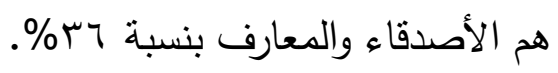

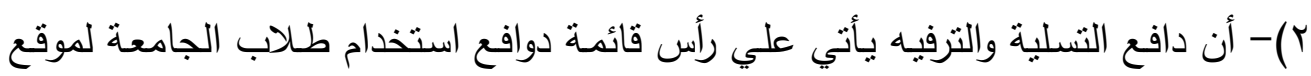
الفيس بوك

ץ)- لا توجد علاقة بين الطريقة التي يقدم بها طلاب الجامعات أنفسهم للآخرين علي موقع الفيس بوك والجامعة التي يدرسون بها.

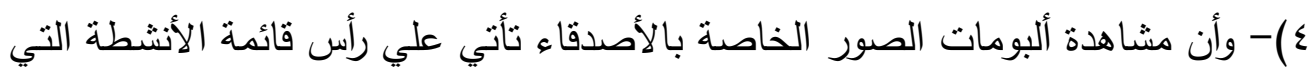

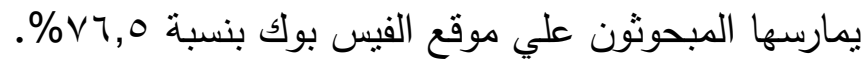

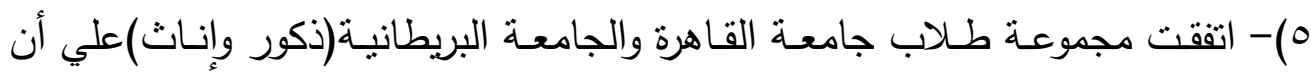
التفاعل الاجتماعي بين الأشخاص عبر موقع الفيس بوك يؤدي إلي تتمية المهارات

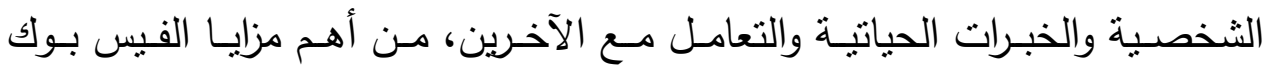

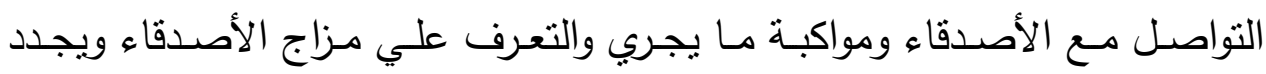
العلاقات بأصدقاء الماضي وإبداء الرأي الحر . ثانيا: الدراسات المتعلقة بالعمل التطوعي: تعددت وتتوعت الدراسات ذات العلاقة المباشرة بموضوع العمل التطوعي ، فعلي صعيد الدراسات العربية عقد 


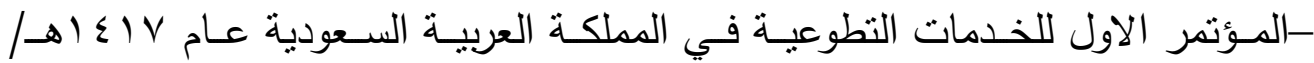

- مؤتمر التطوع الاول لجمعية متطوعي الامارات المنعقد في الثارقة عام 999 (م - مؤتمر العمل التطوعي والامن في الوطن العربي الذي نظمته اكاديمية نايف العربية

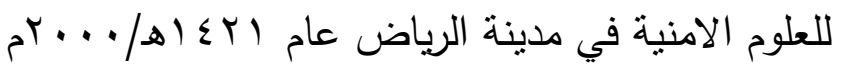
- منتدى الثباب العربي الثاني جول العمل التطوعي عطاء وتتمية والمنعقد في مدينة

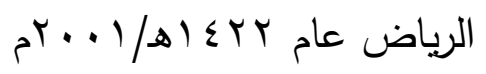
شهدت هذه المؤتمرات العديد من الدراسات وأوراق العمل والتقارير التي اسفرت عن عدد

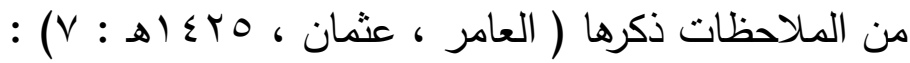
•أن هـذه الدراسـات قد تتاولت علاقـة العمـل التطـوعي بالعديـ مسن المحساور كـالأمن بمفهومه الثامل، وسبل تفعيل الدعوة الإسلامية، والرعاية الاجتماعية في مجال الطفولة والمعوقين والمسنين، والتكافل الاجتماعي وتقديم المساعدات المتتوعة. •أن بعض هذه الدراسات تفتقر إلي العمق النظري والمنهجي في تأصبل قضـايا العمل التطوعي وإثكالاته إذ جاء أغلبها في صورة أوراق عمل أو عرض لبعض التجارب في المؤسسات الخيرية، أو تقارير إحصائية عن المنظمات الأهلية في بعض الدول العربية، أو رؤي مستقبلية تعبر عن الطموح في الزبادة الكمية والنوعية لتلك المؤسسات وسبل دعمها ماليا ، و هي محاور تكررت كثيرا بحكم حرص المشاركون علي عرض تجارب المؤسسات في مختلف الأقطار العربية. •أن بعض الدراسات التي شملتها نلك المؤتمرات ركزت علي التأصيل الإسلامي للعمل التطوعي والأهمية التي يوليها القرآن والسنة للمشروعية هذا الحل وفضله والحث عليه وجزاء المتطوعين. •تتنمي معظم هذه الدراسـات إلي النمط الوثائقي في عرض تاربخ المؤسسات الأهلية الخيريـة وإدارتها وأنشطتها، أو تطورها ودعمها بالنظريـات الحديثة والمشـاريع التتمويـة فيها والفئات المستفيدة من هذه الانشطة ،واللوائح والنظم التي تحكم أدائها. 
•أن السمة الغالبة علي اهتمام هذه الدراسات هو التركيز علي قضايا ومحاور تتصل

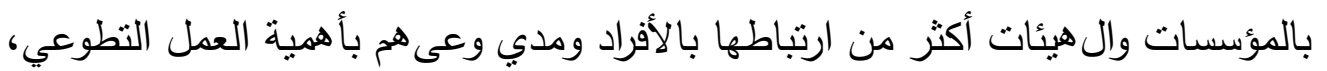

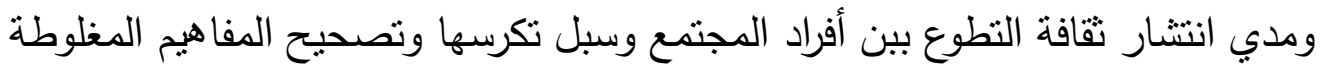

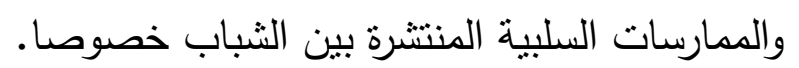
وقد لاحظت الباحثة نقصـا في الأبحاث والدراسـات العربيـة التي ركزت علئ لئي الأفراد

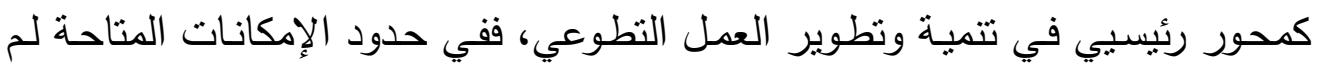

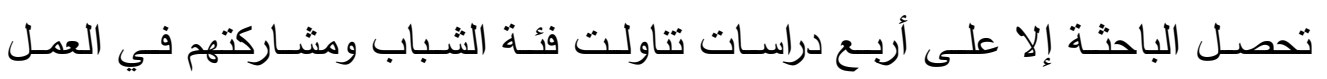

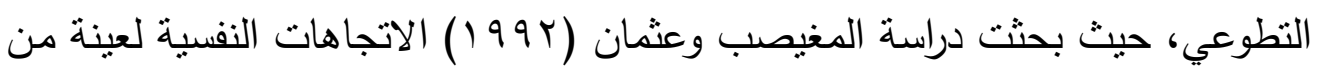
الثباب القطري نحو العمل الاجتمـاعي التطوعي، وتوصلت الدراسـة إلي العديد من دن

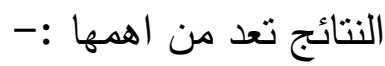

•أن الثباب عينة الدراسة لدى هم اتجاهات إيجابية نحو العمل الاجتماعي التطوعي.

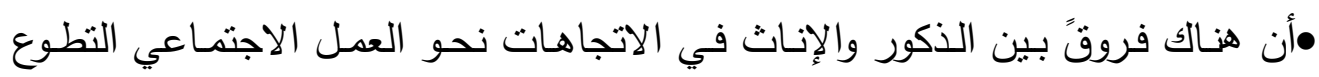
لصالح الإناث. وتتاولت دراسة الثبراوي(ب9 99 ( ) معوقات مشاركة المواطنون في مشروعات الجمعيات

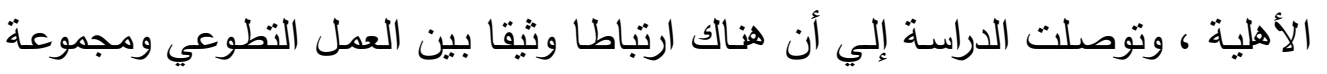
من العوامل منها: حب الخير والتدين والالتزام بالقيم الإسلامية والولاء للوطن. وهدفت دراسة الراشد (ب99 199) إلي استكثاف اتجاهات عينة من الثباب بدولة الإمارات

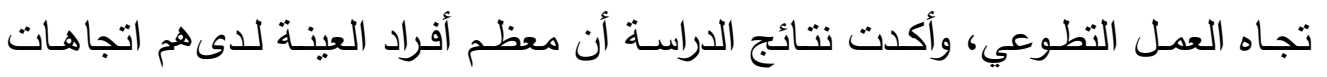
إيجابية نحو العمل النطوعي، وأن هناك فروقا ذات دلالة إحصائية بين الذكور والإناث في الاتجاهات نحو العمل التطوعي لصالح الذكور .

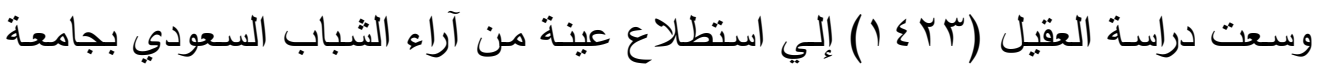

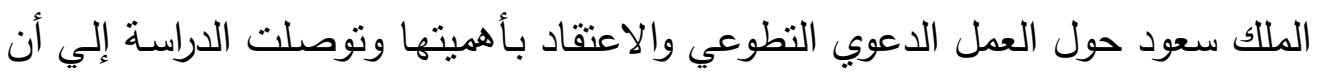

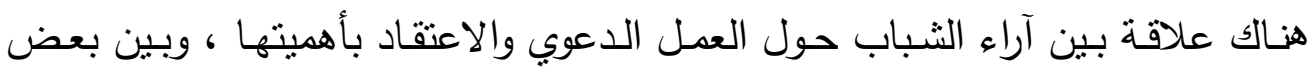

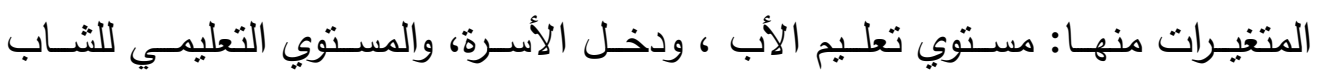


والتخصص، وأوصت الدراسـة بإيجاد آليات توعويـة وتثقفيـة لتوجية طاقات الثنباب وتوظيفها في نشر الدعوة في الداخل والخارج.

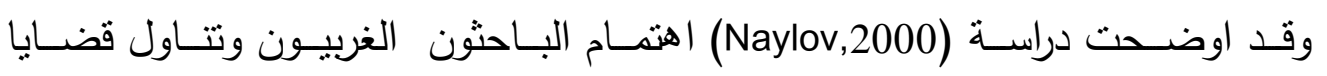

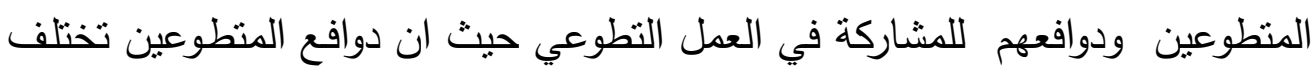

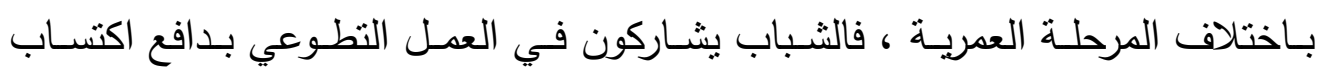

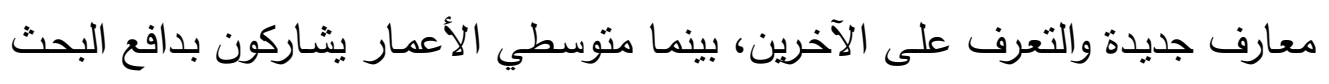

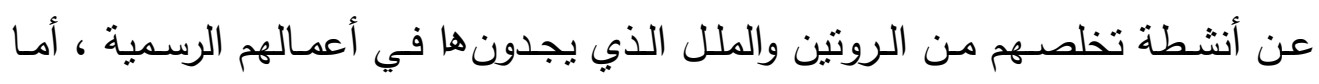
المسنون فدافعهم للعمل التطوعي الوطني هو البحث عن أدوار جديدة لهم في الحياة

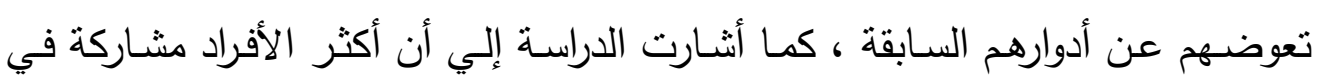

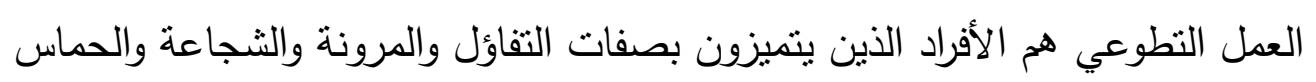

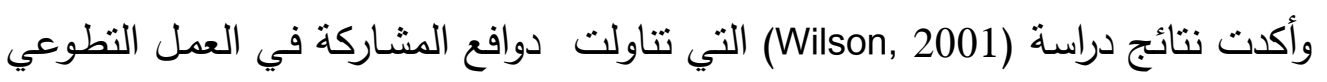

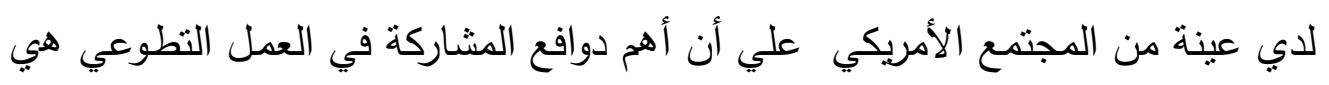

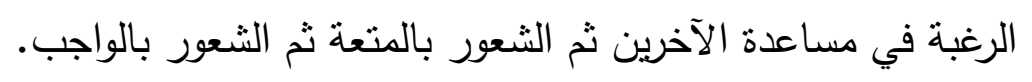

\section{التعليق علي الدراسات السابقة}

من خلال العرض السابق للاراسات السابقة نستتتج الاتي

اهتمام الثباب بوسائل التواصل الاجتماعيةوقضاء وقت طويل في استخدامها . شغف الثباب وحبهم لوسائل التواصل الاجتماعيةوتفعيله في مجالات حياتهم المختلفة.

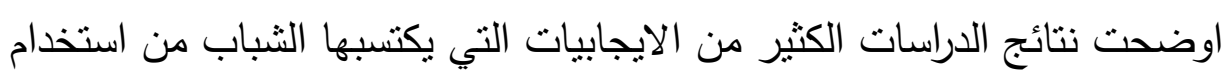
وسائل التواصل الاجتماعية. اوضحت نتائج الدراسات امكانية تفعيل وتوظيف وسائل التواصل الاجنماعية في اكساب الثباب العديد من المهارات والقيم الايجابية . اوضحت الدراسـات السابقة اهية تتمية التطوع والايجابيات التي يكتسبها الثباب من التهابه العمل النطوعي. 
ولاحظت الباحثة من خـال الدراسـات السابقة قلـة وندرة الدراسـات التي توضـح فاعلية

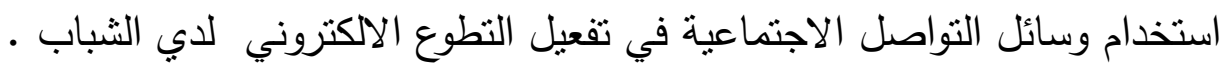

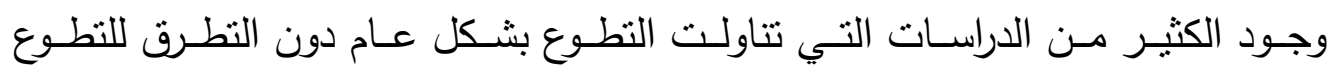
الالكتروني لاحد انواع التطوع الذي اوجدته مستحدثات عصر التكنولوجيا. أداة الدراسة

تعتمد الدراسة علي الاستبيان كأداة لجمع المعلومات والبيانات من عينة الدراسة حيث يحتوي علي جزأين: الأول يبحث في خصنيائص أفراد العينـة كالفئة العمريـة والمعدل

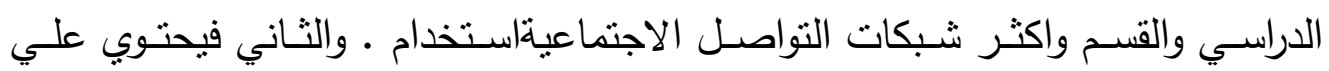
عبارات او فقرات ذات أبعاد التعرف علي مدى وعي الثنابات السعوديات باستخدامات

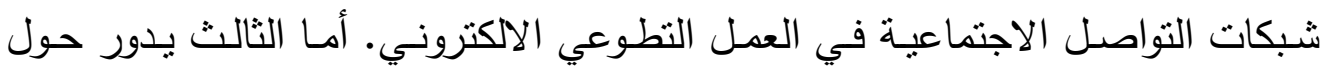

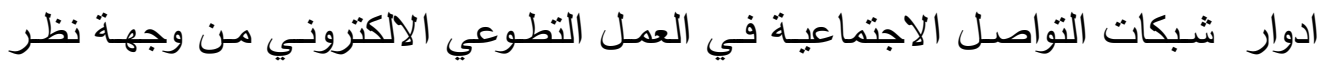

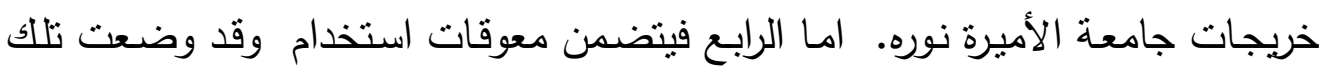
العبارات علي مقياس "ليكرت الخماسي" بحيث أعطي ه درجات للموافق جدا ب درجات للموافق و ץ للمحايد ودرجنين للغير موافق ودرجة للغير موافق بشدة. صدق المقياس (construct Validity): للتحقق من صدق ودنئ الأداة تم استخدام طريقة صدق المحتوى بأسلوب صدق المحكمين (Truth of) Judge حيث وزع المقياس في

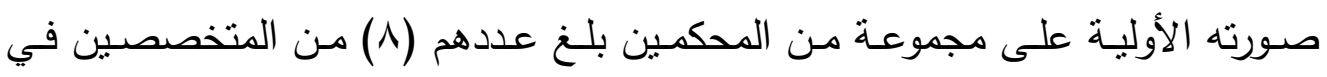

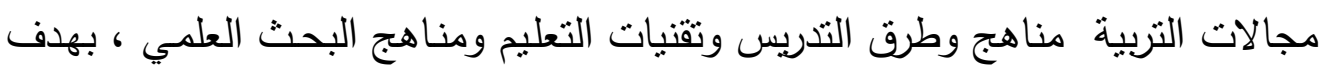

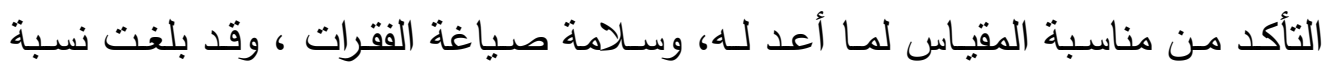

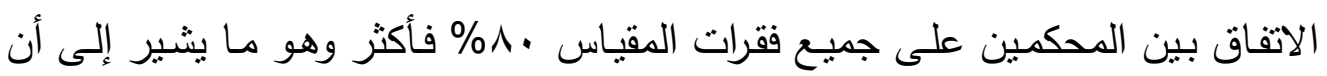
المقياس يتمتع بصدق مقبول، وتم إجراء بعض التعديلات على الصياغة اللغوية للفقرات

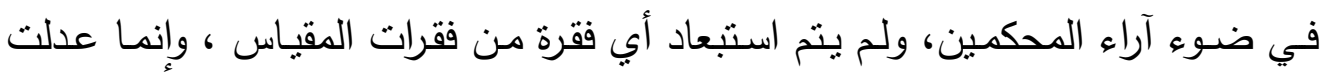

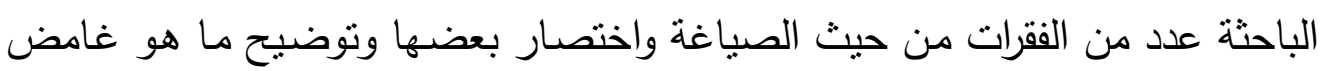


ثبات أداة الدراسة: قامت الباحثة باحتساب ثبات المقياس بعدة طرق على النحو التالي:

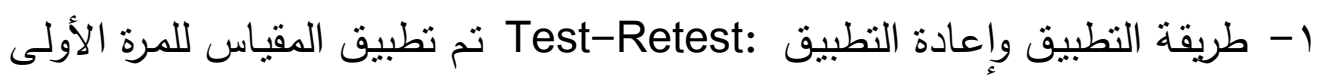

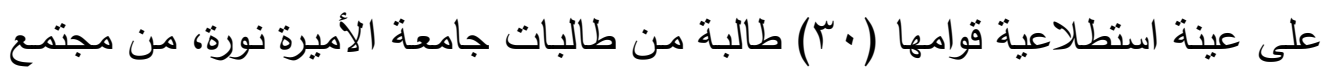

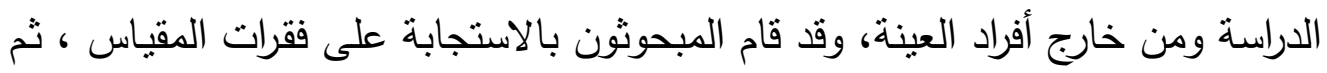

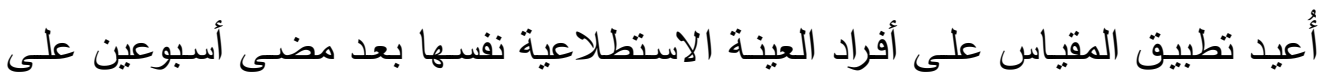

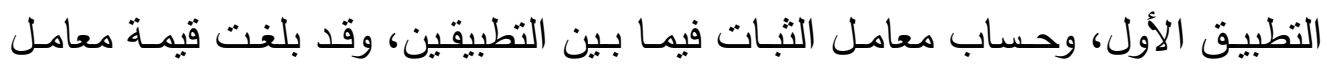
الثبات على الدرجة الكلية للقلق بين مرتي التطبيق (19, · ) وهو معامل ثبات مرتقع و مناسب لأغراض الدراسة. ץ- طريقة التجانس الداخلي (Consistency) من أجل فحص ثبات أداة الدراسة وهذا النوع من الثبات يشير إلى قوة الارتباط بين الفقرات في أداة الدراسـة وذلك باستخدام

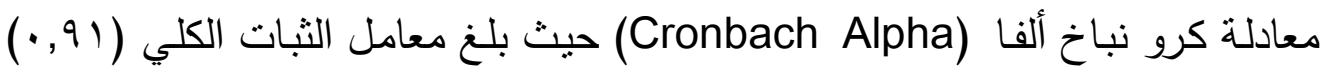

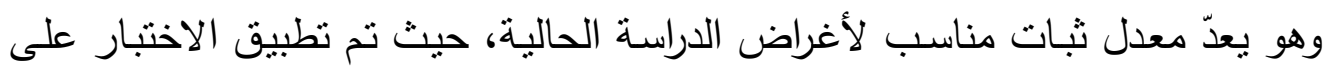

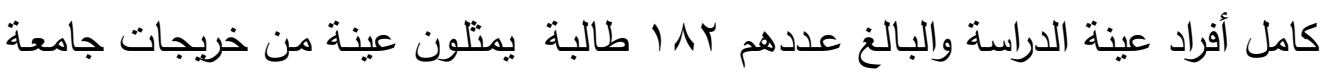
الأميرة نورة.

\section{نتائج الاراسة} : للإجابة عن التساؤل الأول: أولاً ما اكثر وسائل التواصل الاجتماعية أستخداماً لدي خريجات جامعة الأميرة نورة؟ الغيج جدول ( r): يوضح وسائل التواصل الاجتماعيةالاكثر استخداما لدي خريجات جامعة الأمبرة نوره

\begin{tabular}{|c|c|c|}
\hline النسبة & التكرارات & وسامعة الأميرة نوره التواصـل الاجتماعيـةالاكثر اسـتخداما لـدي خريجـات \\
\hline$\% r \varepsilon, Y r$ & Tro & التوتير Twitter \\
\hline$\% \varepsilon \cdot, 1$ & r40 & الانستجرام Instagram \\
\hline
\end{tabular}

Doi: 10.12816/0037192 
مجلة الدراسات التربوية والانسانية ـ كلية التربية ـ جامعة دمنهور. المجلد السابع - العدد(ץ)- لسنة ه 1 ـ r

\begin{tabular}{|c|c|c|}
\hline$\% \vee, 1 \leq$ & 10 & الواتساب WhatsApp \\
\hline$\% \backslash \wedge, 1 \Gamma$ & 170 & Snapchat السناب شات \\
\hline$\% १, १$ & 9 . & Facebook الفبس بوك \\
\hline
\end{tabular}

يثير الجدول رقم ( r) أعـلاه الى أن التكرارات ونسبتها المئويـة لاستجابات خريجات جامعة الأميرة نوره على اكثر وسـائل التواصل الاجتماعية استخداما كانت الانستجرام

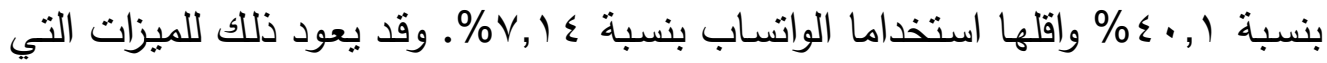
يتميز بها الانستجرام حيث يمكن تتزبل التطبيق على عدد مختلف من الاجهزة سواء كمبيوتز أو الاجهزة الذكيـة الاخرى بالاضـافة الى انـه يعتبر مخزن مؤشفـ للصسور الثخصية والذكربات مـع امكانية معرفة تاريخ انزال الصور وامكانية التعليق عليها من قبل الاصدقاء وابداء الاعجاب بها وتغبير الفلاتر من قبل الثخص وربطها بموقع انزال الصورة وارفاقها بوسم معين لسهولة البحث عنها وغيرها من المميزات. ثانيا: للإجابة عن التساؤل الثاني عن ما مدي الوعي بأهمية العمل التطوعي من وجهة نظر خريجات جامعة الأمبرة نوره ؟ جدول رقم (r): يوضح مدي الوعي بأهمية العمل التطوعي من وجهة نظر خربجات جامعة الأميرة نوره

\begin{tabular}{|c|c|c|c|c|c|c|c|c|c|c|c|}
\hline \multicolumn{2}{|c|}{ خير مواق بشدة: } & \multicolumn{2}{|c|}{ خير ماتق } & \multicolumn{2}{|c|}{ مدبِ } & \multicolumn{2}{|c|}{ مواقق } & \multicolumn{2}{|c|}{ ماتق بشّد: } & \multirow{2}{*}{ العبرة } & \\
\hline لتسبة & انكراد & لالنسبة & لانكررا & لنسبة & التكرلد & لنسبة & النكرئ & لتسبة & لالكترا & & \\
\hline$\%,, T$ & r & $\% r, \varepsilon$, & 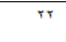 & $\%$, & $\div$ & \%or,: & $\varepsilon \wedge \varepsilon$ & $\% \&$ \&,Y & Tat & ب بع العصل التطوعي مطتب & , \\
\hline$\% 1, r$ & " & $\%$ r, & ז & $\begin{array}{r}\quad, 44 \\
\%\end{array}$ & in & $\%$ \% & צ & $\% า \varepsilon, 9$ & aq1 & 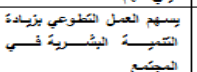 & $T$ \\
\hline$\%, \mathrm{rv}$ & ? & $\% \cdot, \mu$ & $\wedge$ & $\% \tau, \cdot \ldots$ & is & $h_{1, \varepsilon}$ & 17 & $\%$ \% & $\mathrm{v} \cdot$ & 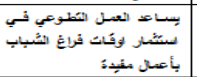 & $T$ \\
\hline$\%$ & , & $\% 1, A \gamma$ & iv & $\% r, 4 y$ & $\mathrm{TV}$ & $\% T r, T T$ & דיוז & $\%\urcorner \varepsilon, \wedge \varepsilon$ & อ9. & 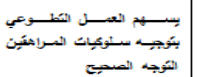 & 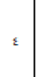 \\
\hline$\%, \mu$ & ^ & $\% 1, \varepsilon T$ & it & $\% T, T r$ & $r$. & $19, \mathrm{TY}$ & 194 & $\%$ vo, ar & 79. & 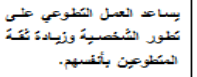 & 。 \\
\hline$\%, r, r$. & יזי & $\% 1, A v$ & 194 & $\% 9, \mathrm{TY}$ & $\mu$ & $\% r, \mu$ & 14. & $T \varepsilon, \Upsilon \uparrow \%$ & זיז & 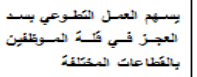 & 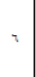 \\
\hline 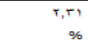 & $r$ & $\% r, i r$ & $\pi$ & $\% \cdot \mu$ & $\wedge$ & \%rr,or & $T A V$ & $\%$ & ודים & 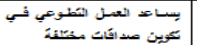 & v \\
\hline$\% 0, \varepsilon T$ & it & $\%$ & $\therefore$ & $\% 1, \tau$ & ז & $\% T 4,7 v$ & $\mathrm{TV}$. & $9 \times 7,+T$ & $\because$. & 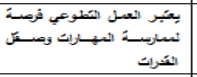 & ^ \\
\hline$\% r, \varepsilon r$ & Tt & $\% r, q v$ & iv & דיה, & ד & $\% T T, T r$ & TVo & \%trivo & ax. & 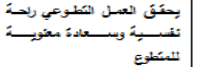 & १ \\
\hline
\end{tabular}


يشير الجدول رقم (ץ): أعـلاه الى أن التكرارات ونسبتها المئويـة لاستجابات خريجات

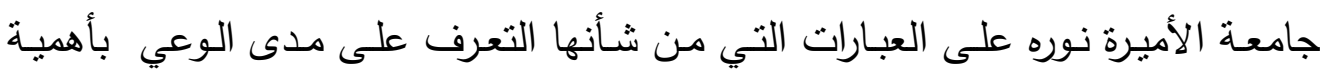

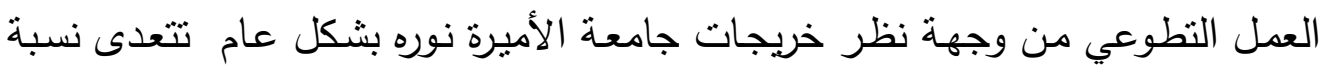

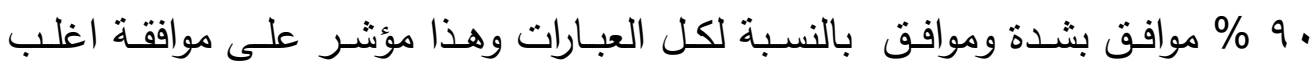

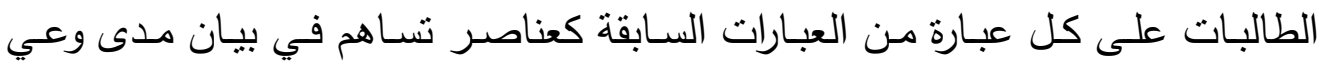

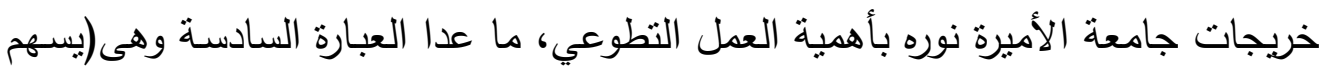
العمل التطوعي بسد العجز في قلة الموظفين بالقطاعات المختلفة) حيث كانت النسبة

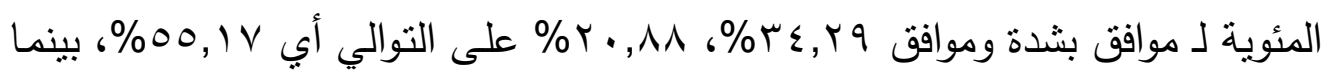

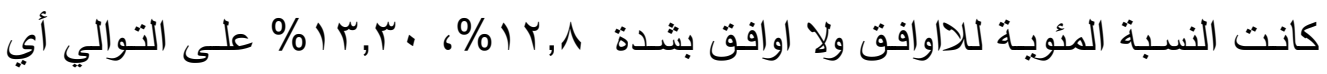

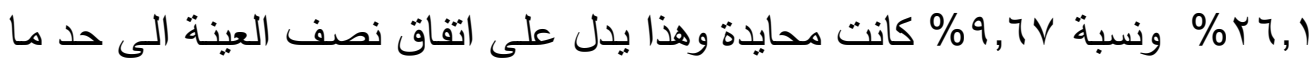
في اسهام العمل التطوعي بسد العجز في قلة الموظفين بالقطاعات المختلفة بشكل عام بينما النصف الاخر كانت غير موافقة والبعض الاخر محايد مما يدل على عدم الاتفاق

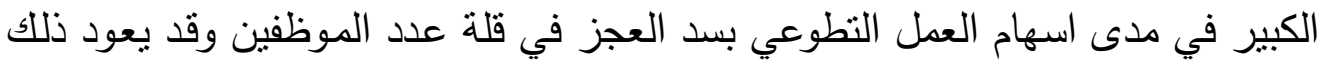
الى ايمان العينـة باهمية العمل الرسمي في القطاعات المختلفة وايمانهم بوجود ايدي

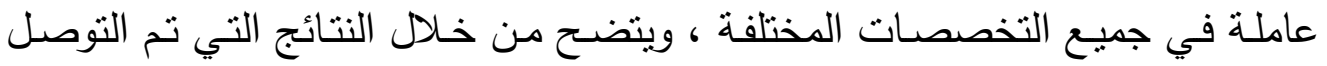

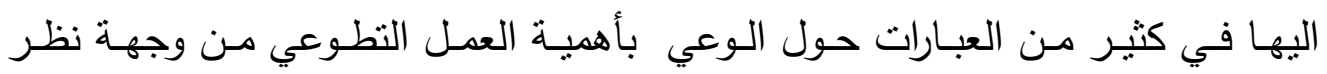

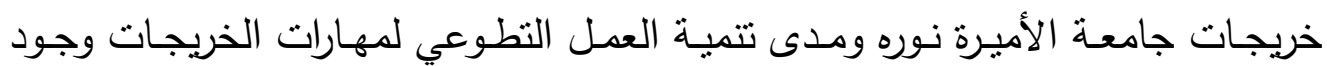
اتفاق كبير بين الخريجات نظرا لارتفاع النسب المئويـة للتكرارات في استجابة موافق لنقون

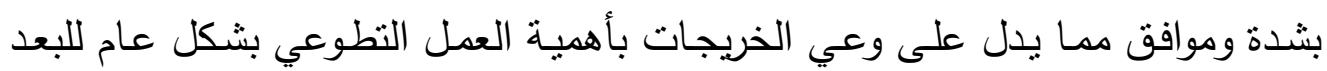
الاول من الاستبانة. 
مجلة الدراسات التربوية والانسانية ـ كلية التربية ـ جامعة دمنهور. المجلد السابع - العدد(ץ)- لسنة ه 1 ـ ب

ثالثاً: الاجابـة عن التسـاؤل الثالث: ما ادوار شبكات التواصل الاجتماعية في تفعيل

النطوع الالكتروني من وجهة نظر خريجات جامعة الأميرة نوره ؟ الابه

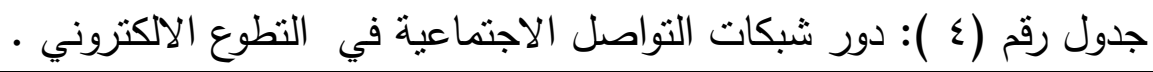

\begin{tabular}{|c|c|c|c|c|c|c|c|c|c|c|c|}
\hline \multicolumn{2}{|c|}{ غير موافق بثدة } & \multicolumn{2}{|c|}{ غير موافق } & \multicolumn{2}{|r|}{ 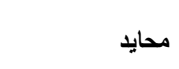 } & \multicolumn{2}{|r|}{ موافق } & \multicolumn{2}{|c|}{ موافق بشدة } & \multirow{2}{*}{ العبارة } & \multirow{2}{*}{ ? } \\
\hline النسبة & رالتــرا & النسبة & التكرار & النسبة & التكرار & النسبة & التكرار & النسبة & التكرار & & \\
\hline \%., \& \& & $\varepsilon$ & $\% 1, r Y$ & it & $\%, r r$ & $r$ & $\% r v, \leftleftarrows v$ & $r \leqslant 1$ & $\begin{array}{r}7,1\} \\
\%\end{array}$ & 00. & 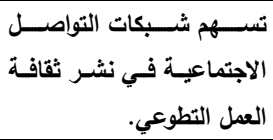 & 1 \\
\hline$\% \cdot, 74$ & 1 & $\% 1,40$ & 10 & - ,99 & 9 & $\%$ o. & $\{00$ & $\% \leqslant ४, \vee$ & \& ro & 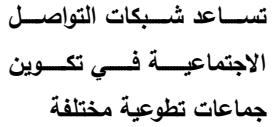 & r \\
\hline$\% \cdot, \vee v$ & v & $\% 1, r)$ & 11 & $1, \mathrm{~V} 4$ & 18 & $\% \leqslant r, q 0$ & ral & \%०r,r & $\varepsilon \wedge 0$ & 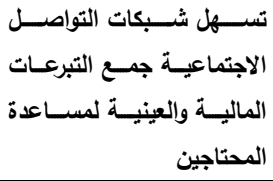 & $r$ \\
\hline $\begin{array}{r}\cdot, \mathrm{VV} \\
\%\end{array}$ & v & $\% 1,0 \leq$ & $1 \leqslant$ & $r, . q$ & 19 & $\% \leqslant 9, \leqslant 0$ & $\leqslant 0$. & $\begin{array}{r}\leq 4,10 \\
\%\end{array}$ & $\varepsilon r$. & 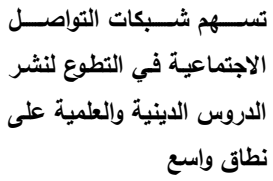 & ๕ \\
\hline $\begin{array}{r}\cdot, \varepsilon \leq \\
\%\end{array}$ & $\varepsilon$ & $\begin{array}{r}1, \cdot 9 \\
\%\end{array}$ & 1. & $\cdot, \wedge \wedge$ & $\wedge$ & $\%$ ๕ . & MI & $\begin{array}{r}01,70 \\
\%\end{array}$ & $\varepsilon v$. & 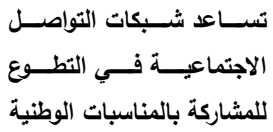 & - \\
\hline$\% \cdot, 99$ & 9 & $\% 1, r)$ & 11 & 1,1 & 1. & $\%$ \% ^,,. & $\leqslant \leqslant$ & $\begin{array}{r}\varepsilon \vee, \wedge . \\
\%\end{array}$ & \& ro & 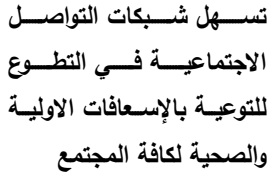 & 9 \\
\hline$\% 1, r r$ & ir & $\% 1,10$ & 10 & $\begin{array}{r}10,1 \\
\%\end{array}$ & 10 & $\%\{\wedge, 1 \Psi$ & $\varepsilon$ & $\begin{array}{r}\varepsilon v, r_{0} \\
\%\end{array}$ & $\varepsilon r$. & 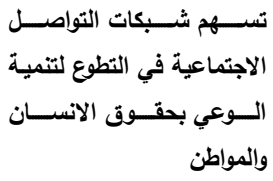 & v \\
\hline$\% \cdot, r r$ & r & $\begin{array}{r}1, \mathrm{~V} 4 \\
\%\end{array}$ & 14 & $\begin{array}{r}1, r Y \\
\%\end{array}$ & ir & $\% ०,, 99$ & 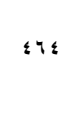 & $\begin{array}{r}\{0, v 1 \\
\%\end{array}$ & $\$ 14$ & 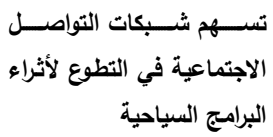 & $\wedge$ \\
\hline$\% 1,\{\wedge$ & 9 & $\begin{array}{r}1,91 \\
\%\end{array}$ & 14 & .9 .8 & 19 & $\% \leqslant r, r$. & ras & $\begin{array}{r}01,70 \\
\%\end{array}$ & $\varepsilon v$. & 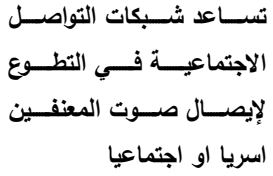 & 9 \\
\hline
\end{tabular}

$\mu$ 
دور شبكات التواصل الاجتماعية في تفعيل التطوع الالكتروني فى جامعة الأميرة نورا د. أمل القحطانى

\begin{tabular}{|c|c|c|c|c|c|c|c|c|c|c|}
\hline $\begin{array}{r}r, r . \\
\%\end{array}$ & r. & $\begin{array}{r}v, r_{1} \\
\%\end{array}$ & ๕ & $\begin{array}{r}\varepsilon, 11 \\
\%\end{array}$ & $\mu_{\Lambda}$ & $\% ๕ ৭, \vee \wedge$ & sor & $\begin{array}{l}r v, r v \\
\%, q)\end{array}$ & $r \leqslant 0$ & 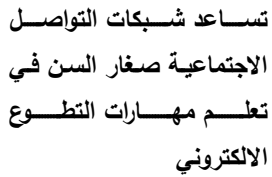 \\
\hline
\end{tabular}

يشير الجدول رقم ( ع) أعلاه الى أن التكرارات ونسبتها المئوية لاستجابات خريجات جامعـة الأميرة نورة على العبارات التي من شـأنها التعرف على دور شبكات التواصل الاجتماعية في التطوع الالكتروني من وجهة نظر خريجات جامعة الأميرة نوره بشكل عام تتعدى نسبة . ^ \% موافق بشدة وموافق بالنسبة لكل العبارات وهذا مؤشر على موافقةاغلب الطالبات الخريجات على كل عبارة من العبارات السابقة كعناصر تساهم في بيـان ادوار شـبكات التواصـل الاجتماعيـة في التطـوع الالكتروني مـن وجهـة نظـر خريجات جامعة الأمبرة نوره بشكل عام ويتضح من خلال النتائج التي تم التوصل اليها في كثير من العبارات حول ادوار شبكات التواصل الاجتماعيـة في التطوع الالكتروني من وجهة نظر خريجات جامعـة الأمبـرة نـوره وجـود اتفـاق كبيـر بـين الخريجـات نظـرا لارتفـاع النسـب المئويـة للتكـرارات في اسـتجابة موافـق بثـدة وموافـق ممـا يـدل على ادوار واسـهامات شـبكات

التواصل الاجتماعية في التطوع الالكتروني بشكل عام للبعد الثاني من الاستبانة. رابعاً: الاجابـة عن التساؤل الرابـع: ما معوقات تفعيل التطوع الالكتروني عبر شبكات

التواصل الاجتماعية من وجهة نظر خريجات جامعة الأميرة نوره ؟ جدول رقم (0): معوقات تفعيل التطوع الالكتروني عبر شبكات التواصل الاجثماعية.

\begin{tabular}{|c|c|c|c|c|c|c|c|c|c|c|c|}
\hline \multicolumn{2}{|c|}{ غير موافق } & \multicolumn{2}{|c|}{ غير موافق } & \multicolumn{2}{|c|}{ محايد } & \multicolumn{2}{|c|}{ موافق } & \multicolumn{2}{|c|}{ موافق بشدة } & \multirow{2}{*}{ العبارة } & \multirow{2}{*}{ م } \\
\hline النسبة & s & النسبة & ك & النسبة & ك & النسبة & s & النسبة & 5 & & \\
\hline $\begin{array}{r}\varepsilon, \gamma_{0} \\
\%\end{array}$ & rq & $\%$ \%, १V & $\wedge \wedge$ & $\% 0,7$ & 01 & $\% \leqslant \wedge, r_{0}$ & $\leq \varepsilon$. & \% rT,IV & $r \cdot r$ & 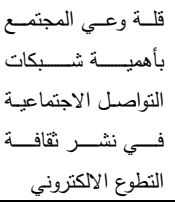 & 1 \\
\hline$\% 1,1$ & 1. & $\%$ \%,r. & r. & $\% 1,7 \leqslant$ & 10 & $\% 04, Y 4$ & 011 & $\% r \wedge, \vee q$ & ror & بأهمية البرامج التوعيل التطويـة & r \\
\hline
\end{tabular}

Doi: $10.12816 / 0037192$

r. 
مجلة الدراسات التربوية والانسانية ـ كلية التربية ـ جامعة دمنهور. المجلد السابع - العدد(ץ)- لسنة ه 1 ـ ب

\begin{tabular}{|c|c|c|c|c|c|c|c|c|c|c|c|}
\hline & & & & & & & & & & 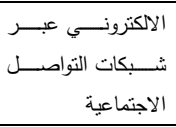 & \\
\hline$\% 1$ & 9 & $\% 1, r T$ & ir & $\% \cdot$, TV & 1 & $\% \circ \vee, 1 \leqslant$ & or. & $\% r q, q$ & זדי & 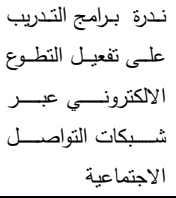 & $r$ \\
\hline $\begin{array}{r}\text { Or, }\left\{\begin{array}{r} \\
\%\end{array}\right. \\
\end{array}$ & rr & $\% 04,9$. & $\begin{array}{l}01 \\
1\end{array}$ & $\%$ \% ,Aт & ז & $\% 1,1$ & 1. & $\% 0,9$ & m & 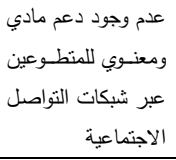 & $\varepsilon$ \\
\hline $\begin{array}{r}1,0 \leqslant \\
\%\end{array}$ & $1 \varepsilon$ & $\% \circ, v)$ & or & $\% \curlyvee, . \leqslant$ & 00 & $\% \varepsilon \wedge, \uparrow \wedge$ & $\leq \leqslant r$ & $\%$ \%,$\cdot r$ & $r \leqslant \tau$ & 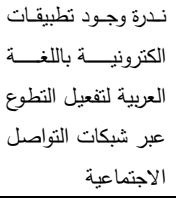 & 。 \\
\hline $\begin{array}{r}1, \varepsilon \wedge \\
\%\end{array}$ & 9 & $\% \varepsilon,, 7\rceil$ & r & $\% \vee v, \vee$. & $\varepsilon \vee \leqslant$ & $\% \varepsilon, v r$ & $\varepsilon r$ & $\% 1$, or & $1 \leq$ & 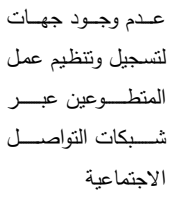 & 7 \\
\hline $\begin{array}{r}\cdot, 99 \\
\%\end{array}$ & 9 & $\% r, \cdot \wedge$ & rA & $\% \curlyvee, A Y$ & r & $\% \varepsilon r, \wedge \varepsilon$ & एव१ & $\% \leqslant q, r r$ & $\leq \leqslant \wedge$ & 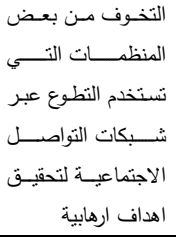 & v \\
\hline $\begin{array}{r}\text { l, YA } \\
\%\end{array}$ & 17 & $\% \curlyvee, \neg \varepsilon$ & $r \varepsilon$ & $\%$ \%,AT & Y & $\% \leqslant 0, \leqslant 9$ & \&1 & $\% \leqslant v, r_{0}$ & $\varepsilon r$. & 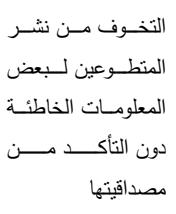 & $\wedge$ \\
\hline $\begin{array}{r}\cdot, Y V \\
\%\end{array}$ & v & $\% \curlyvee, \leqslant \curlyvee$ & rY & $\% r, \cdots$ & 19 & $\% \varepsilon \wedge, r \leqslant$ & $\varepsilon r q$ & $\% \leq 4, \leqslant \wedge$ & $\varepsilon r T$ & 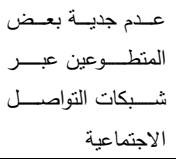 & 9 \\
\hline
\end{tabular}

وصـلت هنـا يثــير الجـدول رقم ( (0) أعـلاه الـى أن التكـرارات ونسـبتها المئوبـة لاستجابات خريجـات جامعـة الأميرة نوره على العبارات التي من شـأنها التعرف على تسـاهم في بيان رأي الخربجـات حول أسباب معوقات تفعيل التطوع الالكتروني عبر شـبكات التواصـل الاجتماعيـة بشـكل عـام تتعـدى نسبة ، م \% موافق بشـدة وموافق بالنسبة لكل العبارات عدا العبارة السادسة والسابعة والثامنة وهذا مؤثر على موافقة اكثر T.o 
من نصف الطالبات على كل عبارة من العبارات السابقة كعناصر نساهم في بيان رأي

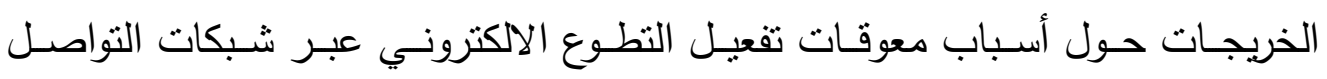
الاجتماعية ما عدا العبارة الرابعة وهى (عدم وجود دعم مادي ومعنوي للمتطوعين عبر شبكات التواصل الاجتماعية) ويتضـح من خلال النتائج التي تم التوصل اليها في كثير من العبارات حول معوقات

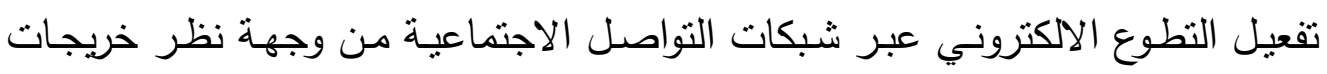

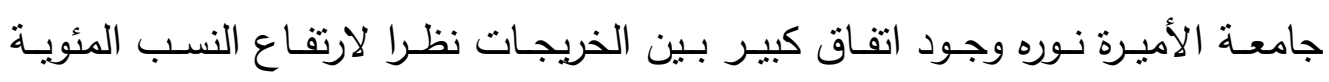

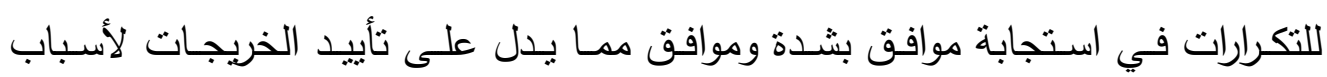

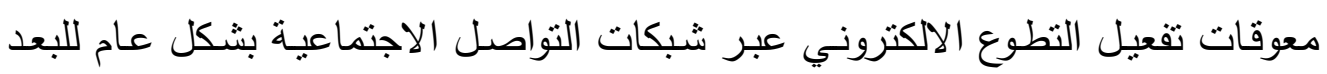
الثالث من الاستبانة

الاجابة عن التساؤل الخامس: ما هي اهم الاعمال التطوعية التي يمكن القيام بها عبر

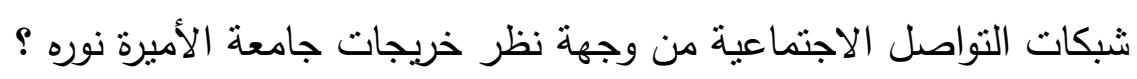
جاءت بعض اجابات الطالبات علي النحو التالي :

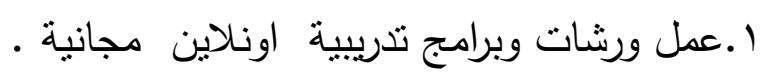

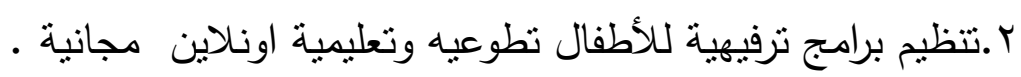

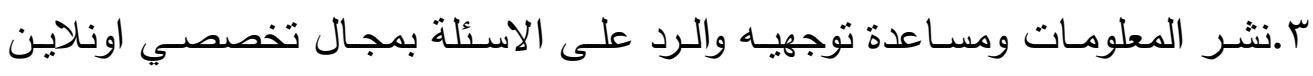
مجانية. ع .مسـاعدة محتــاج وتوصـيل صـوته لأكبـر شـريحة مدكنـة عبـر وسـائل التواصـل

$$
\text { الاجتماعي. }
$$

ه.تكوين جماعات الكترونية من الخدمات المساندة لأسر ذوي الاحتباج الخاص.

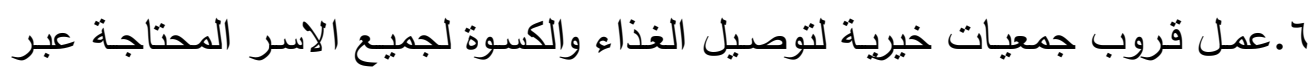
التأكد من وضعهم عبر مؤسسة الجمعيات الخيرية .

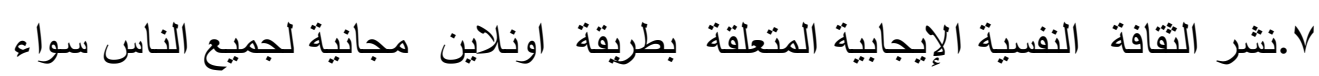
كانوا أسوياء أو غير أسوياء . 
مجلة الدراسات التربوية والانسانية ـ كلية التربية ـ جامعة دمنهور. المجلد السابع - العدد(ץ)- لسنة ه 1. ب

^.جمـع الصـدقات وتبرعـات واعطائهـا للمحتـاجين مـن خـلال وسـائل التواصـل

$$
\text { الاجتماعي. }
$$

التوصيات والمقترحات

• دعم الأبحاث والمشروعات العلمية التي تسهم في بناء بيئات افتراضية تواصلية

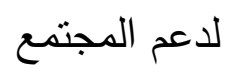

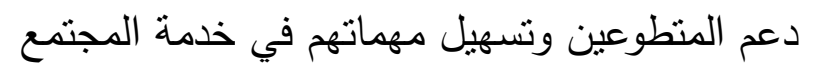

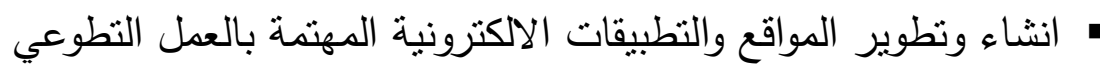

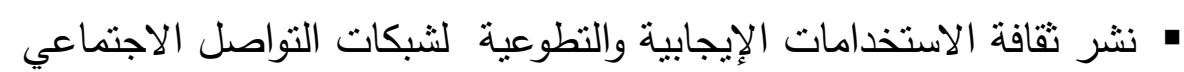

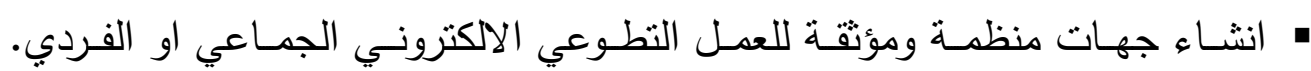




\section{قائمة المراجع}

أولاً: المراجع العربية

1- السيد أحمد عمر ، البحث العلمي مفهومه وإجراءاته ومناهجه (ليبيا: منشورات جامعة قاريونس،

$$
\text { .. M ص (1998 }
$$

r-بن رحومة،علي ميلاد (Y . . r) علم الاجتماع الآلي ، سلسلة عالم المعرفة، المجلس الوطني للتقافة

$$
\text { والاداب والفنون ، الكويت. }
$$

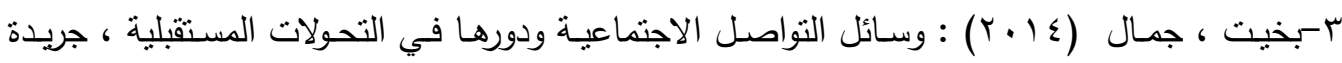

$$
\text { السياسة ، العدد } 17048
$$

ع - الآثار النفسية والاجتماعيـة لاستخدام الثباب المصـرى لمواقع الثبكات الاجتماعيـة: دراسـة على ،لى

مستخدمي الفيس بوك. بحث مقدم للمؤتمر العلمي الاول بعنوان: الاسرة وتحديات العصر مأ-

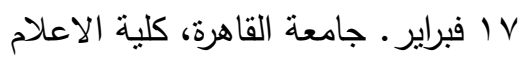

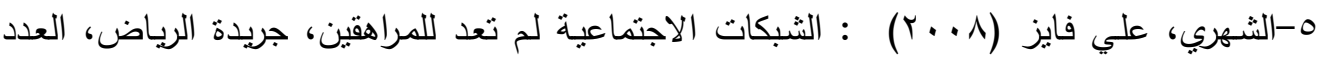
14776

צ- نريمان،مواقع التواصل الاجتماعيةو أثنارها الأخلاقية و القيمية، مذكرة تخرج ماجيستير قسم الدعوة

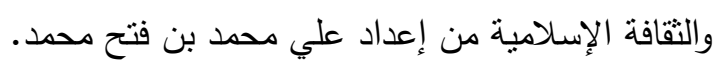

V-عوض، حسني : دراسـة أثر مواقع التواصل الاجتماعيةفي تتمية المسؤولية الاجتماعية والمشاركة

المجتمعية لاى الثباب -تجربة مجلس شبابي علار ، جامعة القدس المفتوحة

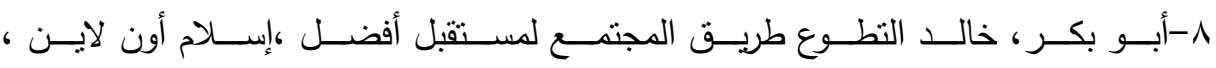
http://www.islamonline.net/Arabic/index.shtml

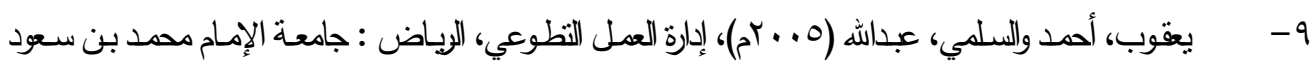

$$
\text { الإسلامية، عمادة البحث العلمي. }
$$

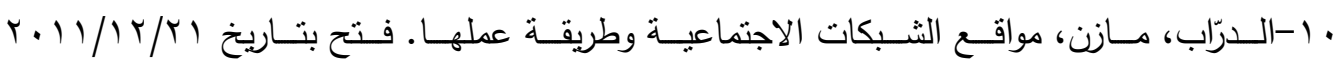
knol.google.com/k

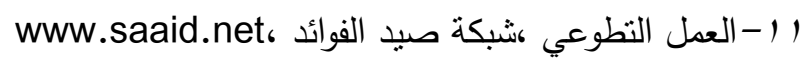

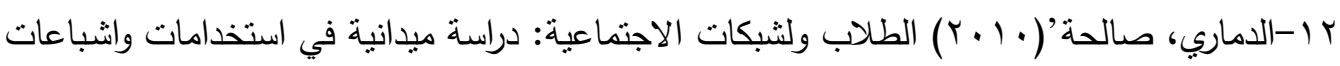

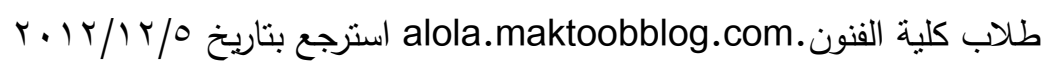

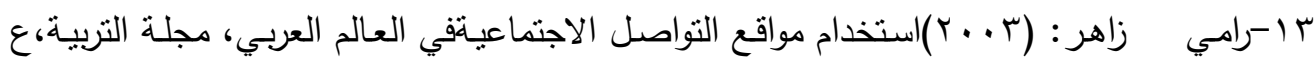

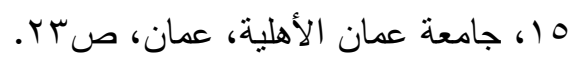

Doi: $10.12816 / 0037192$ 
ع ا- سـاري ،حلمي خضر : تأثير الاتصال عبر الانترنيت في العلاقات الاجتماعية (دراسـة ميدانية

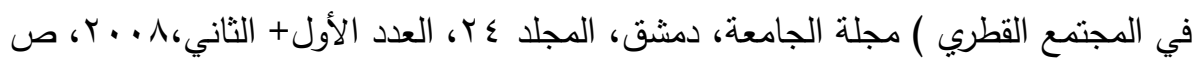
.r.

1 1 -إبراهيم النملة ،علي محاضرة العمل الخيري الإسـلامي في ضوء التحديات المعاصرة. الدكتور وزير الثؤون الاجنماعية سابقاً. الجامعة الإسلامية بالمدينة المنورة

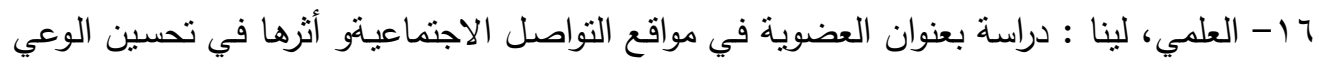
الاجنمـاعي السياسـي لـى طلبـة جامعـة النجـاح الوطنيـة ، مشـروع تخـرج، جامعـة النجـاح

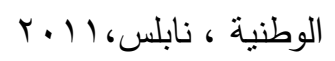
IV V

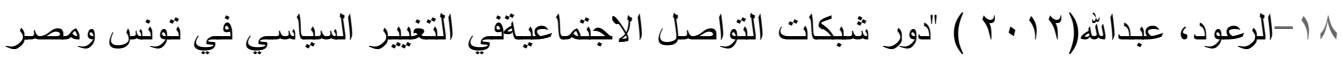
من وجهة نظر الصحفيين الاردنيين"، رسالة ماجستير غير منشورة، جامعة الشرق الاوسط:كلية لام الاعب

http://publications.iua.edu.sd/iua_magazine/sharuea_magazine/6/006.

$\underline{\mathrm{pdf}}$

9 ا - عبد الجليل، موسى آدم (11 • (1) كيف ساهمت وسائل التواصل الاجتماعيةفي اضعاف العادات

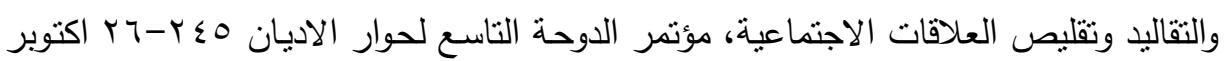

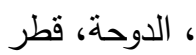
• ץ-عبد السـلام، نجوى(991 (1) أنمـاط ودوافـع اسـتخدام الثـباب المصـري لشبكة الانترنت، المؤتتمر العلمي الرابع: الاعلام وقضايا الثباب، جامعة القاهرة، كليبة الاعلام.

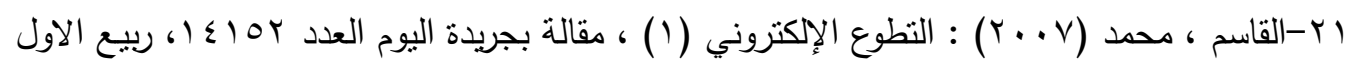

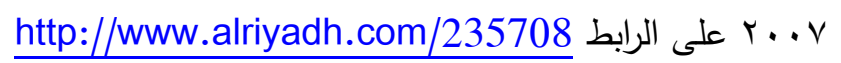

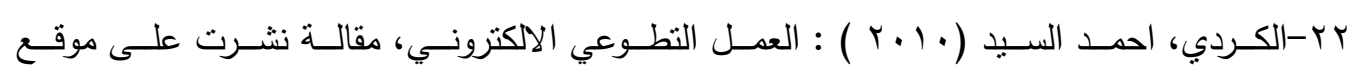
http://kenanaonline.com/users/ahmedkordy/posts/129432 بr-نزال، عمـاد؛ حبش ، جمال (10 • ( ) : التطوع الالكتروني وسيلة معززة للعمل التطوعي، مجلة

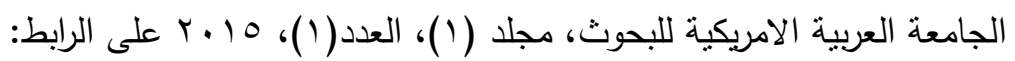

http://goo.gl/QIm2IW

ـ ؟- ورقلـة ، ناديـة ، دراسـة بعــوان: دور شـبكات التواصـل الاجتماعبـةفي تتميـة الـوعي السياسـي

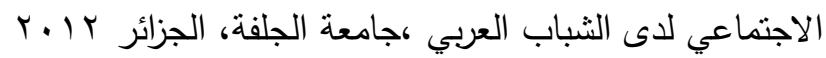


هץ-المحاميد، محمد (1 + . r م). دوافع السلوك التطوعي النسوي المنظم في الأردن وعلاقته ببعض

المتغيرات الاجتماعية والاقتصادية والتعليمية، رسالة ماجستير ، الجامعة الأردنية بعمان.

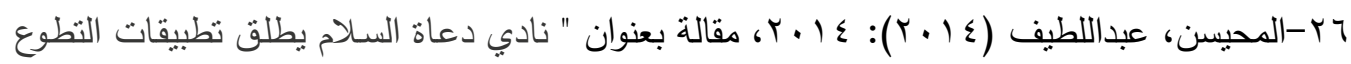

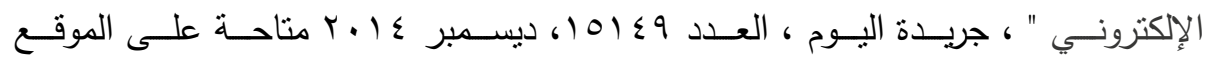

http://www.alyaum.com/article/4032048

rr - مركز شؤون المراة - غزة (11 • r) استطلاع للراي العام حول شبكات التواصل الاجتماعية اجري

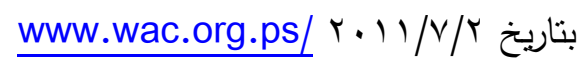

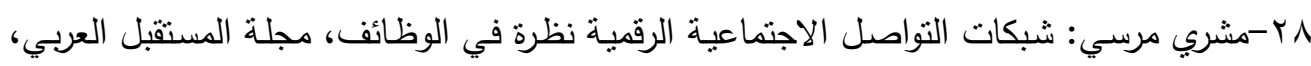

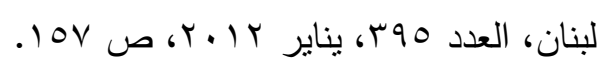

و ج- الموسى، عصام (9 . . r) المدخل في الاتصال الجماهيري، الطبعة السادسة، عمان، اثراء للنشر والتوزبع.

• ץ- مؤتمر الاعـلام لاسـلامي (11 • ب): تأثثر شبكات التواصل على الربيع العربي، تونس، جامعـة بنزرت.

اب- الموسوي، محمد (ع . ب)، النظرية الاعلامية، جامعة البحرين، كلية التربية. بr- الوفائي، محمد(9/9 (19) مناهج البحث في الدراسات الاجتماعية والاعلامية ،القاهرة، مكتبة الانجلو المصرية.

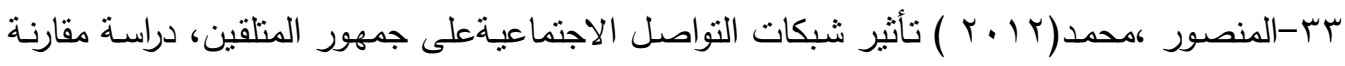
للمواقع الاجتماعية و المواقع الاككترونية "العربية نموذجا" رسالة الماجستير الأكاديمية العربية المفتوحة في الانمارك.

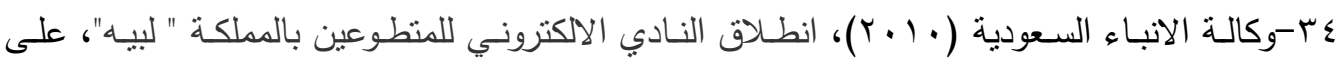

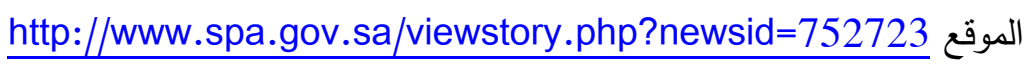

\section{ثانياً: المراجع الأجنية:}

1-Mary, H., A ddescription study of older person performing volunteer work and the relationship to life satisfaction, purpose in lifeand support, Ph.D.,dissertation, University of Laws, 1988.

2-Thomaz Waltz, or others, Environmental Dscyhn, in: Social work Journal, Vol. 9, No. 1, January 1974, pp. 38-46.

3-European Siminar on Function and Training of Voluntary Social Welfare Workers,Federation Republic of Germany, May ,1980,p.52.

Doi: $10.12816 / 0037192$ 
مجلة الدراسات التريوية والانسانية ـ كلية التربية ـ جامعة دمنهور. المجلد السابع - العدد(ץ)- لسنة ه 1 . r

4- Kaiser et al.(1974) Educational and Psychological Measurement (340 Spring.

Katz, et al.," Utilization of Mass Media by Individuals". In Blumler and Katz (ed.),(1974) The uses of Mass Communication. London, Faber2 Faber

5-Kim \& Mueller (1978) Introduction to Facto Analysis: what It is and how to do it. (13) Sage Publications. Beverly Hills. California.

6-McQuail,et al."The Television Audience: A Revised Perspective". In McQuai(ed.), (1972) Sociology of Mass Communication. Harmond worth, Penguin

7-McQuai.D,(1987) Mass Communication Theory. London, Sage Publication ltd. 
دور شبكات التواصل الاجتماعية في تفعيل التطوع الاكتروني فى جامعة الأميرة نورا د. أمل القحطانى 